\title{
High-Reynolds Number Active Blowing Semi-Span Force Measurement System Development
}

\author{
Keith C. Lynn ${ }^{1}$, Ray D. Rhew ${ }^{2}$, Michael J. Acheson ${ }^{3}$, Gregory S. Jones ${ }^{4}$, \\ William E. Milholen ${ }^{5}$, Scott L. Goodliff ${ }^{6}$ \\ NASA Langley Research Center, Hampton, Virginia, 23681
}

\begin{abstract}
Recent wind-tunnel tests at the NASA Langley Research Center National Transonic Facility utilized high-pressure bellows to route air to the model for evaluating aircraft circulation control. The introduction of these bellows within the Sidewall Model Support System significantly impacted the performance of the external sidewall mounted semi-span balance. As a result of this impact on the semi-span balance measurement performance, it became apparent that a new capability needed to be built into the National Transonic Facility's infrastructure to allow for performing pressure tare calibrations on the balance in order to properly characterize its performance under the influence of static bellows pressure tare loads and bellows thermal effects. The objective of this study was to design both mechanical calibration hardware and an experimental calibration design that can be employed at the facility in order to efficiently and precisely perform the necessary loadings in order to characterize the semi-span balance under the influence of multiple calibration factors (balance forces/moments and bellows pressure/temperature). Using statistical design of experiments, an experimental design was developed allowing for strategically characterizing the behavior of the semi-span balance for use in circulation control and propulsion-type flow control testing at the National Transonic Facility.
\end{abstract}

\section{Nomenclature}

AF
AFC
AOA
AMS
ANOVA
CFD
DRM
FAST-MAC
NASA
NF
OLS
NTF
PAI
PM
RCM
RM
SF
SMSS
SPD
SP
VIF
WP
X
Y
YM

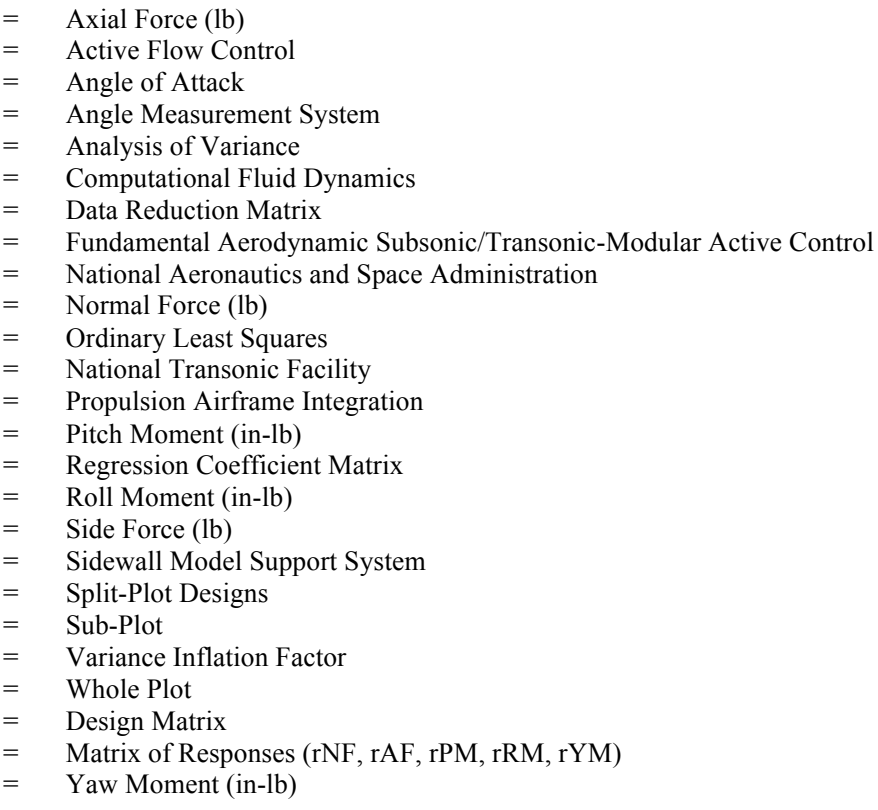

\footnotetext{
${ }^{1}$ Research Engineer, Aeronautics Systems Engineering Branch, Mail Stop 238, AIAA Member

${ }^{2}$ Research Engineer, Aeronautics Systems Engineering Branch, Mail Stop 238, AIAA Member

${ }^{3}$ Project Manager, Technologies Application Branch, Mail Stop 237, AIAA Member

${ }^{4}$ Research Engineer, Flow Physics and Control Branch, Mail Stop 170, AIAA Senior Member

${ }^{5}$ Research Engineer, Configuration Aerodynamics Branch, Mail Stop 499, AIAA Senior Member

${ }^{6}$ Test Engineer, Jacobs Technology, Inc., Mail Stop 267, AIAA Senior Member
} 


\section{Introduction}

A ctive flow control (AFC) continues to be a fertile research field that holds promise to enhance the aerodynamic performance of conventional aircraft and enable the development of unconventional vehicles. A wide variety of $\mathrm{AFC}$ techniques are being pursued, ranging from direct boundary layer manipulation using steady or pulsed blowing methodologies, to indirect methods including induced plasma flows near a surface. Computational Fluid Dynamics (CFD) methods are maturing to the point that they are being used as tools to improve and optimize flow control techniques on realistic configurations. The confidence in these CFD tools can be improved as they are systematically validated. In general, CFD validation is defined by determining how well the CFD model predicts the performance and flow physics when used for its intended purposes. The level of CFD validation can be defined by the complexity of the code and the experiment being used for validation.

Circulation control has reemerged in AFC research. The circulation control method introduces momentum directly to the near wall region via a blowing slot, typically located near the trailing edge and directed over a simple short-cord flap. The resulting simplified high-lift system can generate maximum lift values significantly higher than that of a conventional multi-element high-lift system. On an aircraft, one supply option for the circulation control system is engine bleed air, which was shown to be viable by a recent e-STOL aircraft design study. It is worthy to note that unsteady circulation control methods are also being examined to reduce the bleed air requirements. Another advantage, which has yet to be fully addressed, is the application of the circulation control technique during transonic cruise for either drag reduction or for simplified maneuvering systems.

To address this overarching need, a research project was begun to develop the capability to test AFC concepts and propulsion simulations at high Reynolds numbers in the National Transonic Facility (NTF) at the NASA Langley Research Center. ${ }^{1}$ The new flow control and propulsion simulation capability at the NTF is focused on the use of semi-span models due to the relative ease of routing high-pressure air to the model, and the increased model size compared to a conventional sting mounted full-span model. The increased model size allows higher model fidelity, as well as increased internal volume for housing the flow control mechanisms and instrumentation. A new high-pressure air delivery station has been designed which has a low mass-flow segment for flow control simulations, and a high mass-flow segment for propulsion simulations. Two new wind tunnel models were developed for the initial testing with this air station. The first is a simple model, which employs two check-standard nozzles to verify the operational characteristics of the air station. The second model is a high-performance transonic wing that will be used to evaluate various circulation control concepts at both transonic cruise conditions, as well as low-speed high-lift conditions. The modular design employed for the new transonic semi-span model is emphasized, as it can readily be reconfigured for testing other flow control techniques. Lastly, a new higher load capacity semispan force and moment balance has been completed and calibrated for the transonic testing. ${ }^{2}$

In order to route high-pressure air out to the semi-span model, the NTF air station was designed as a dual flow air delivery system capable of providing two independently controlled air lines to the semi-span model via a set of concentric air lines. These dual air lines are coupled to the semi-span model via a concentric set of bellows (low \& high mass flows), and a model interface choke plate. Both the high and low flow legs of the system can provide up to $1200 \mathrm{psig}$ capability. The high mass-flow leg of the system is capable of providing $0.1-20.0 \mathrm{lbm} / \mathrm{sec}$ of air flow, while the low mass-flow leg is capable of providing $0.1-8.0 \mathrm{lbm} / \mathrm{sec}$ directly to the model. The integration of the new air delivery station and the pressure bellows that will be directly linked to the metric end of the NTF-117S semi-span balance adds a complexity to the system that can impact the performance of the balance. In order to determine the significance of these pressure tare effects on the performance/accuracy of the NTF-117S balance, an experiment was designed involving performing a set of calibration loads on the balance. This calibration process will involve varying the combination of 7 factors (applied NF, AF, PM, RM, YM, static pressures applied to bellows, and bellows average temperature).

With the demand for performing semi-span wind tunnel testing on the rise, the demand to provide highly accurate and precise semi-span force balances has increased. This report provides detail on the design and calibration of a new semi-span balance developed for use at the NTF at NASA Langley Research Center, as well as discusses test data from recent wind tunnel tests that utilized this new measurement capability. 


\section{Background}

\section{A. Test Facility}

There are two general types of balances; internal and external. Internally mounted balances are mounted internal to the wind tunnel model during the testing process. Externally mounted balances, typically referred to as semi-span balances, are mounted external to the wind tunnel model being tested. Semi-span balances are used to test semi-span test models, as shown in Figure 1 below (Fundamental Aerodynamic Subsonic/TransonicModular Active Control (FAST-MAC) semi-span test model, tested at the NTF facility at NASA Langley Research Center). The recent increase in the need for semi-span balances is directly linked to the benefits that semi-span model testing provides over full-span model testing, such as an increased Reynolds number capability, higher model fidelity, reduction in aero-elastic effects during testing, a substantial reduction in the costs associated with model fabrication. ${ }^{3-7}$ It is also significantly easier to supply pressure out to a semi-span model than it is to route the pressure up through a sting, and bridging over an internal force balance. Since most semi-span tests are not concerned with measuring aerodynamic side forces, routing pressure in line with the side

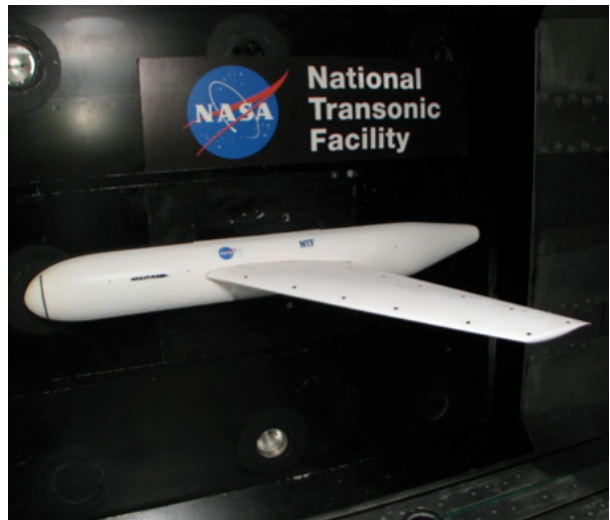

Figure 1. Fundamental Aerodynamic Subsonic/Transonic-Modular Active Control (FAST-MAC) Semi-Span Test at NTF (NASA Langley Research Center) force vector presents less repeatability issues than when trying to route the pressure in-line with the axial force measurement component of the typical internal force balance.

While there are significant advantages to semi-span model testing, there are also several disadvantages. These disadvantages include increased negative impacts due to tunnel wall interference, interaction of air-flow over the semi-span model with the tunnel wall boundary layer, and thermal stability issues that are observed by the externally mounted semi-span force balances ${ }^{5,7,8}$. While each of these negatively impacts data accuracy, a significant amount of research has been performed to determine any proper corrective measures.

The NTF is a cryogenic, high-pressure, closed-circuit wind tunnel facility that was developed in the 1970's due to the increased need for a facility that was capable of providing high Reynolds number testing capabilities. ${ }^{9,10}$ The need for this high Reynolds number capability allows for simulating full-scale aircraft operating conditions. The NTF is a fan-driven facility with a test section that measures $8.2^{\prime} \times 8.2^{\prime} \times 25^{\prime}$, and has both slotted floors and ceilings to help prevent any near-sonic flow 'choking' effects. The facility operates over a dynamic press range of $15-125$ psia and $+150^{\circ} \mathrm{F}$ to $-260^{\circ} \mathrm{F}$, which yields Mach numbers ranging from 0.2-1.2. In order to test at cryogenic temperatures, liquid nitrogen (LN2) is injected into the tunnel directly up-stream of the fan and this liquid nitrogen evaporates resulting in a cool down as a result of the heat of vaporization and latent heat. By testing with liquid nitrogen as the test medium, the resulting increased Reynolds number capability is achieved through reducing the kinematic viscosity and increasing the density of the air stream. ${ }^{10}$ When testing in air, the heat is removed from the tunnel by an upstream water-cooled heat exchanger.

In order to conduct semi-span model tests, the model is supported in the tunnel by the SMSS. Before mechanically attaching the model to the SMSS, a segment of the test section wall is removed so that the SMSS can be installed behind the test section. Once the SMSS is attached to its appropriate structure behind the tunnel wall, the removed test section wall is re-installed. The center of the SMSS (and semi-span balance) is located 13 feet aft of the plane where the test section begins. When the semi-span model is mounted, it is mechanically joined to the semi-span balance by fastening it to the SMSS top-hat adapter. During model installation a stand-off is place in between the test section wall and the model, to help reduce any negative effects between the interaction of the sidewall boundary layer and the performance of the semi-span model.

\section{B. NTF-117S Balance Design \& Instrumentation}

In recent years the NTF has devoted a considerable amount of effort in developing its semi-span model testing capability $^{3-5,7}$. The increased interest in semi-span testing at the NTF has sparked the development of new balance 
design requirements, which in turn resulted in the development of new semi-span balances capable of measuring the aerodynamic loads on these semi-span test models. Initially, a single semi-span balance was designed (NTF-114S) that had a NF measurement capability of $6,100 \mathrm{lb}$. The NTF-114S semi-span balance has traditionally been used primarily for high-Reynolds number testing for low-speed high-lift model configurations. ${ }^{2}$ As new semi-span model configurations and testing technologies continue to be developed that will require testing at high-speed transonic testing regimes, the required NF measurement capability needed at these testing conditions surpasses the capability of the existing NTF-114S balance. The limited measurement capability of the existing NTF-114S semi-span balance prompted the development of the new NTF-117S balance ${ }^{2}$, which has a NF measurement capability $(12,000$ lb) that nearly doubles that of the NTF-114S. Table 1 below compares the design loads for both the NTF-114S and NTF-117S, to show the increase in measurement capability as a result of the development of the new NTF-117S balance.

Table 1. Current NTF Semi-Span Balance Capabilities

\begin{tabular}{|c|c|c|c|c|c|}
\hline & NF (lb) & AF (lb) & PM (in-lb) & RM (in-lb) & YM (in-lb) \\
\hline NTF-114S & 6,100 & 1,300 & 70,000 & 353,800 & 75,400 \\
\hline NTF-117S & 12,000 & 1,800 & 90,000 & 670,000 & 100,000 \\
\hline
\end{tabular}

As seen in Figure 3, the balance has flange type mounting interfaces on both the metric and non-metric interfaces, which allow for rigidly attaching the non-metric end of the balance to the SMSS, and the metric end of the balance to the semi-span model (with a thermal insulation disk located between the balance and top-hat, to decrease thermal gradient effects). The balance was designed with an 8.0" diameter hole down its centerline, which accommodates all of the wiring and instrumentation that is routed between the semi-span model and the data acquisition system. As will be discussed in a later section, the hole down the centerline of the balance will be used as a passage way to route high-pressure air lines from the NTF high-pressure air-station, and out to the semi-span models.

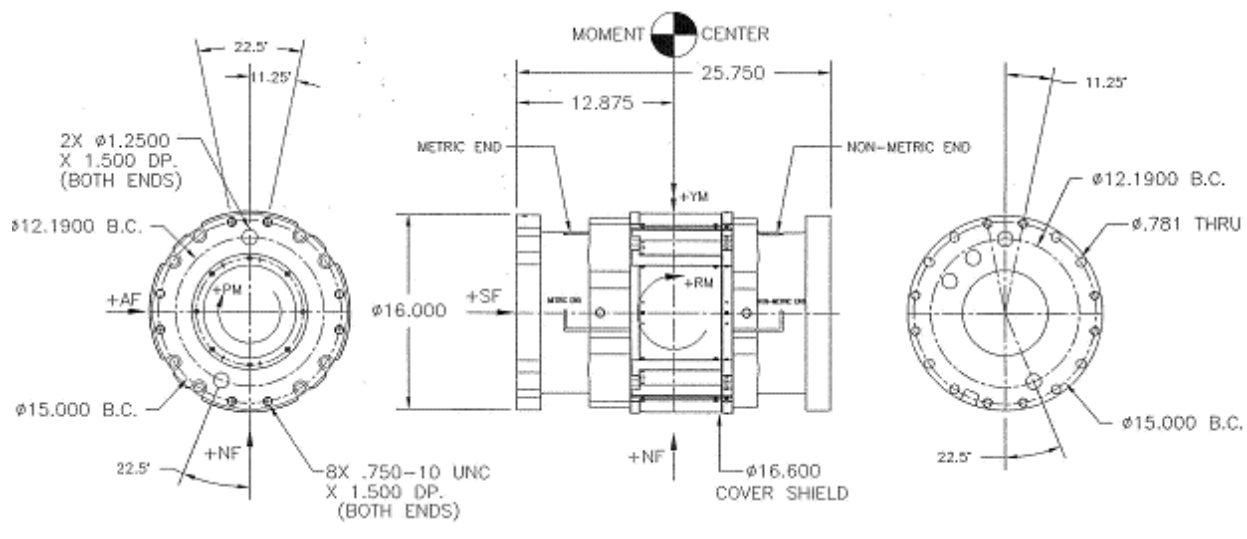

Figure 2. NTF-117S Critical Dimensions

The NTF-117S balance is instrumented with 5 primary and 5 secondary strain gage circuits, wired into doubleWheatstone bridges to reduce both interaction and thermal gradient effects. The primary and secondary bridges are excited separately using two power sources that supply 5 volts to a set of main terminals located on the balance. +/Power, monitor, and sense leads are wired to the main terminals where the bridge circuits terminate and are paralleled wired. This allows the voltage to be monitored and sensed as close to the bridges circuits as possible, while reducing the number of lead wires that exit the transducer to a data system. 


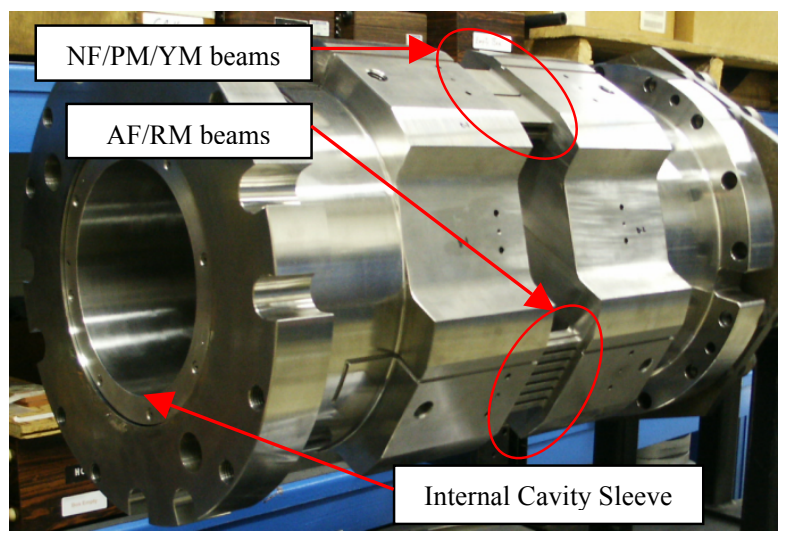

a)

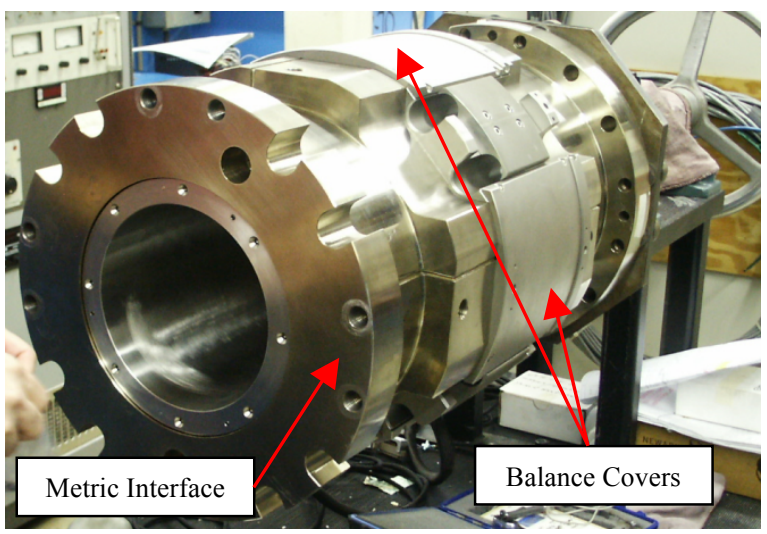

b)

Figure 3. NTF-117S Semi-Span Balance, a) w/o external balance covers, b) w/ external balance covers

The balance reference coordinate system is shown in Figure 4, used to define all balance frame forces/moments during the calibration and use during testing.

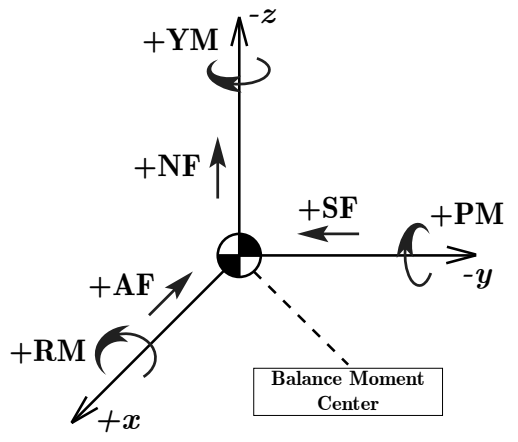

Figure 4. Balance Reference Coordinate System

In addition to the strain gage instrumentation, a total of 32 PRT's are are distributed throughout the balance such that both the global temperature profile can be observed, as well as being able to measure the local temperatures near the strain gage locations. The balance also has an on-board AOA measurement package, which provides an absolute reference of the balance and model pitch attitude (angle-of-attack) during testing. This AOA was operational during the calibration of the balance, and was used to compare the pitch deflection measurements from the AMS (which was mounted to the calibration hardware during the duration of the calibration). The difference in the pitch measurement between the AOA and AMS packages provides an estimate of the pitch deflections induced on the balance and calibration hardware as a result of the applied calibration loads. Figure 5 below shows some of the instrumentation (strain gages, AOA package) installed on the NTF-117S balance.

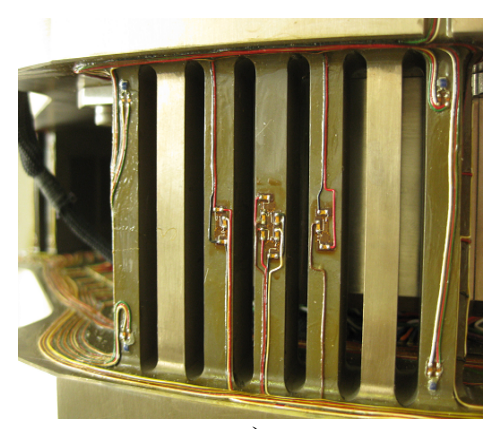

a)

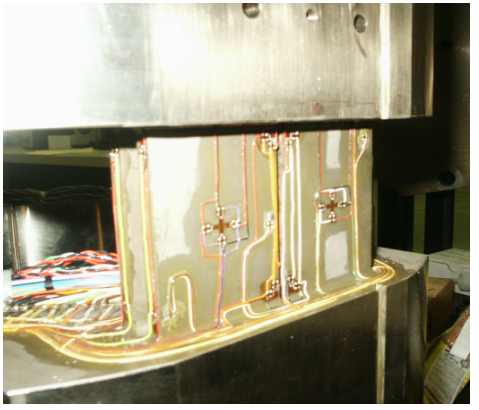

b)

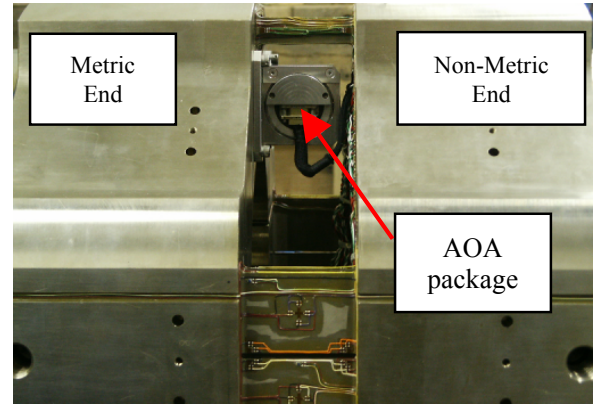

c)

Figure 5. a) AF/RM flexure beams, b) NF/PM/YM flexure beams, c) on-board AOA measurement package 


\section{Balance Standard Calibration}

The most critical portion of the balance design process is the balance calibration, which is the process by which known loads are applied to the balance and the measured responses from each of the measurement bridges are recorded. The purpose of performing a balance calibration is to develop a mathematical model that characterizes the behavior of the balance. This mathematical model is used to estimate the aerodynamic loads imparted on the balance during the wind tunnel test. As a general procedure, when calibrating a force balance a set of pre-determined independent variables (applied calibration loads) are applied to the balance, and the resulting dependent variables (electrical output response of each measurement bridge) are recorded. The range of the calibration loads applied to the balance during the calibration process defines the 'design space'. Historically, the load schedule used to calibrate a balance (which defines the load combinations and the order that they are to be performed) has been a standardized process that is the same for all balance types. NASA Langley's traditional calibration model is based on a Taylor series, and is given by:

$$
y=\beta_{o}+\sum_{i=1}^{k} \beta_{i} x_{i}+\sum_{i=1}^{k-1} \sum_{j=i+1}^{k} \beta_{i j} x_{i} x_{j}+\sum_{i=1}^{k} \beta_{i i} x_{i}^{2}
$$

where $\mathrm{k}$ is the number of independent variables $(\mathrm{k}=5), x_{i}$ 's are the $i$ th independent variable, and the $\beta$ 's represent the calibration coefficients determined from a multiple linear regression procedure. For a standard six-component balance, there are 6 main-effect terms, 15 two-factor interactions and 6 pure quadratic terms. The calibration coefficients are included within a calibration matrix, which is essentially a curve-fit to the calibration data. Based on Eq. (1) above, $1+2 k+[k(k-2) / 2]$ calibration points are required with at least 3 unique levels of each independent variable in order to estimate the model terms for a full quadratic model with $k$ number of independent variables.

When characterizing any balance, it is critical to perform a sufficient number of independent calibration loads such that all the model terms can be independently estimated. Each term in the mathematical model represents certain physical properties of the balance. The linear interactions can be attributed to machining errors, errors in both location and alignment of strain gages, and variations in the gage factor for the strain gages. The first-order interaction terms are typically associated with the magnitude of the deflections present during loading of the balance. Typical balance calibrations have all been conducted with only applied loads as being the calibration factors, but it is possible to include additional factors, such as pressure and temperature, within the calibration design if it is suspected that they have an effect on the response $(s)^{21}$.

The original calibration of the NTF-117S force balance involved applying different load combinations to the balance with dead weights (shown in Figure 6), where these dead weights are applied to precisely defined load points on the balance calibration hardware. The balance is supported on the non-metric end by mechanically grounding it to a calibration stand, which supports the balance during the application of all calibration loads. The calibration stand has actuators that allow for re-leveling the balance in both pitch and roll after each load is applied, to ensure that applied loads are orthogonal with the balance coordinate system before the data acquisition system collects the data for that load point. For the calibration of the NTF- $117 \mathrm{~S}$ balance, 62 different loading sequences were performed, with each sequence containing 5 increments ( 0 load, $50 \%$ load, $100 \%$ load, $50 \%$ load, 0 load). Of these 62 different loading sequences, combinations of single and multi-component loading were applied to the balance, providing a total of 310 data points to be used estimating the mathematical calibration model.

Of the 310 total load points performed during the calibration, 280 points were used to build the calibration model, and 30 points were used as confirmation points. The 30 confirmation points are a set of independent used to validate the prediction capability of the calibration model. Each of the 62 loading sequences were performed at a nominal ambient room temperature. The calibration loads are transferred through a configuration of double knifeedge decoupling devices, which are used to minimize coupling of unwanted moments on the balance during calibration. With most manual calibration systems, there are limitations that prevent being able to apply pure moments during the calibration. In order to simulate applying pure moments, the long-arm calibration technique is used where all moments are applied to the balance by applying small magnitude loads to calibration arms that are relatively long. This process helps minimize inaccuracies, and helps isolate the interaction effects. ${ }^{12}$ 
The 62 different load sequences used to calibrate the balance were selected to enable for exploring the entire design space capability of the balance. After each of the 310 calibration loads were completed (over the course of 5 weeks), the appropriate 280 data points were used to estimate the mathematical model using least squres regression. Once the calibration coefficients were computed from the data reduction process, the calibration model for each of the balance responses was used to back-calculate the response residuals for all 310 data points (error in the prediction capability of the calibration models).

By using the calibration models to back-calculate the residuals for the calibration data points, the \% full-scale accuracies for each measurement component are computed. The calibration residuals and

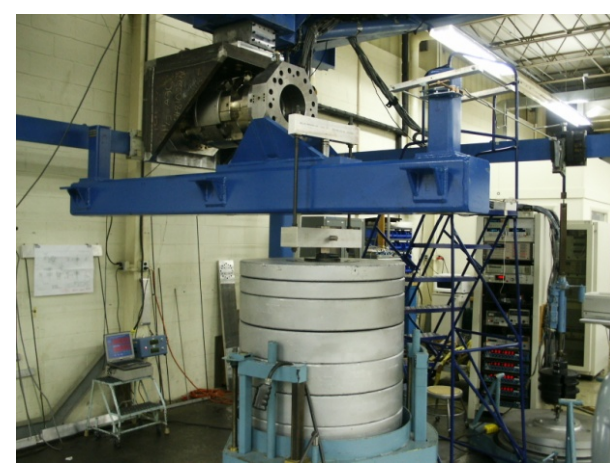

Figure 6. 5.2\% NTF-117S Balance Calibration Setup the resulting measurement accuracy are used to assess the associated measurement accuracy and uncertainty of the balance. There are 3 main sources of uncertainty associated with the calibration; 1) calibration model that is created from the calibration data, 2) the measurement repeatability of the balance, and 3) the uncertainty of the calibration system (hardware, data system) used during the calibration. As seen from the Tables below, all of the individually computed accuracies (from the back-computed residuals) are less than $0.25 \%$ full-scale. The final calibration accuracies and full-scale outputs are provided shown below in Tables 2, and the calibration regression coefficients for each measurement component are contained within Table 3. The accuracy quotes shown in Table 2 represent the prediction accuracy over the full-scale range for each component.

Table 2. Primary Bridge Calibration Results

\begin{tabular}{|c|c|c|c|c|c|}
\hline \multirow{2}{*}{ Component } & Calibration Load Range & $\begin{array}{c}\text { Full Scale } \\
\text { Output } \\
\text { (mV/V) }\end{array}$ & $\begin{array}{c}\text { Sensitivity } \\
\text { Constant } \\
\text { (lb/mV/V) }\end{array}$ & $\begin{array}{c}\text { Accuracy \%F.S. } \\
\text { (two-sigma) }\end{array}$ \\
\cline { 2 - 6 } & $\mathrm{NF}$ & -12000 to $12000 \mathrm{lb}$ & 1.332 & 9010.86 & $\mathbf{0 . 0 5}$ \\
\cline { 2 - 6 } & $\mathrm{AF}$ & -1800 to $1800 \mathrm{lb}$ & 1.224 & 1470.4 & $\mathbf{0 . 1 4}$ \\
\cline { 2 - 6 } & $\mathrm{PM}$ & -90000 to $90000 \mathrm{in}-\mathrm{lb}$ & 1.734 & 51900.06 & $\mathbf{0 . 1 6}$ \\
\cline { 2 - 6 } & $\mathrm{RM}$ & -669000 to $669000 \mathrm{in}-\mathrm{lb}$ & 1.873 & 357224.4 & $\mathbf{0 . 1 2}$ \\
\cline { 2 - 6 } & $\mathrm{YM}$ & -100350 to $100350 \mathrm{in}-\mathrm{lb}$ & 0.291 & 345046.5 & $\mathbf{0 . 0 9}$ \\
\hline
\end{tabular}

Table 3. NTF-117S Balance Calibration Regression Coefficients (0's denote term removed from model during ANOVA)

\begin{tabular}{|c|c|c|c|c|c|}
\hline GAGE OUT NAME & rNF & rPM & rYM & rRM & $\mathbf{r A F}$ \\
\hline INTERCEPT & $1.60564 \mathrm{E}+02$ & $-1.20950 \mathrm{E}+02$ & $-1.38856 \mathrm{E}+02$ & $-6.64028 \mathrm{E}+01$ & $1.29521 \mathrm{E}+01$ \\
\hline NF (x1) & $1.11025 \mathrm{E}-01$ & $-9.68044 \mathrm{E}-04$ & $1.42867 \mathrm{E}-04$ & $2.80835 \mathrm{E}-04$ & $1.28196 \mathrm{E}-04$ \\
\hline PM (x3) & $2.95848 \mathrm{E}-05$ & $1.92697 \mathrm{E}-02$ & $-2.40036 \mathrm{E}-05$ & $-2.43735 \mathrm{E}-05$ & $-4.90413 \mathrm{E}-05$ \\
\hline YM (x5) & $-2.77010 \mathrm{E}-06$ & $1.79854 \mathrm{E}-05$ & $2.89201 \mathrm{E}-03$ & 0 & $-9.56848 \mathrm{E}-05$ \\
\hline RM (x4) & $3.32584 \mathrm{E}-05$ & $-1.55666 \mathrm{E}-06$ & $-5.14725 \mathrm{E}-06$ & $2.79868 \mathrm{E}-03$ & $-2.82064 \mathrm{E}-07$ \\
\hline AF (x2) & $9.48169 \mathrm{E}-03$ & $-3.88319 \mathrm{E}-04$ & $5.76849 \mathrm{E}-03$ & $-6.80751 \mathrm{E}-04$ & $6.80862 \mathrm{E}-01$ \\
\hline $\mathbf{N F} * \mathbf{N F}$ & 0 & 0 & 0 & 0 & 0 \\
\hline $\mathbf{P M} * \mathbf{P M}$ & 0 & 0 & 0 & 0 & 0 \\
\hline $\mathbf{Y M} * \mathbf{Y M}$ & 0 & 0 & 0 & 0 & 0 \\
\hline $\mathbf{R M}$ *RM & 0 & 0 & $-3.45403 \mathrm{E}-13$ & 0 & $2.21075 \mathrm{E}-12$ \\
\hline $\mathbf{A F} * \mathbf{A F}$ & 0 & 0 & 0 & 0 & 0 \\
\hline NF*PM & 0 & 0 & 0 & 0 & $1.57276 \mathrm{E}-09$ \\
\hline NF*YM & 0 & $3.09947 \mathrm{E}-09$ & 0 & 0 & 0 \\
\hline NF*RM & $-5.52829 \mathrm{E}-11$ & 0 & $1.90425 \mathrm{E}-11$ & 0 & 0 \\
\hline NF*AF & 0 & 0 & 0 & 0 & 0 \\
\hline PM*YM & $2.86868 \mathrm{E}-10$ & 0 & 0 & 0 & 0 \\
\hline $\mathbf{P M} * \mathbf{R M}$ & $1.79898 \mathrm{E}-11$ & 0 & $6.40036 \mathrm{E}-12$ & 0 & $1.55642 \mathrm{E}-09$ \\
\hline $\mathbf{P M} \mathbf{A F}$ & 0 & 0 & 0 & 0 & 0 \\
\hline $\mathbf{Y M} * \mathbf{R M}$ & $-8.38589 \mathrm{E}-12$ & $-1.34878 \mathrm{E}-10$ & 0 & 0 & 0 \\
\hline $\mathbf{Y M}$ *AF & 0 & 0 & 0 & 0 & 0 \\
\hline $\mathbf{R M} \mathbf{A F}$ & 0 & $1.43742 \mathrm{E}-08$ & 0 & 0 & 0 \\
\hline
\end{tabular}




\section{Circulation Control \& Propulsion Simulation Testing at NTF}

\section{NTF Air Station}

Recent facility modifications at the NTF have incorporated a high-pressure air station, which is capable of providing high-pressure air to semi-span models that are mounted to the metric end of the SMSS's internal semi-span force balances. In order to route this highpressure air out to the semi-span model, the NTF air station was designed as a dual flow air delivery system capable of providing two independently controlled air lines to the semi-span model via a set of concentric air lines. These dual air-lines are coupled to the semi-span model via a concentric set of bellows (low \& high massflows), and a model interface choke plate. Both the high and low flow legs of the system can provide up to 1200 psig capability. The high mass-flow leg of the system is capable of providing $0.1-20.0 \mathrm{lbm} / \mathrm{sec}$ of air flow, while the low mass-flow leg is capable of providing $0.1-8.0$ $\mathrm{lbm} / \mathrm{sec}$ directly to the model. The air delivery station provides continuous flow of dry air to the semi-span model. Figure 7 depicts a schematic of the SMSS with the high-pressure airflow paths routed through the SMSS and out to the model. Figure 8 shows the NTF wind-tunnel circuit, the location of the SMSS inside the circuit, and a general representation of how the air station provides highpressure air to the model during testing.

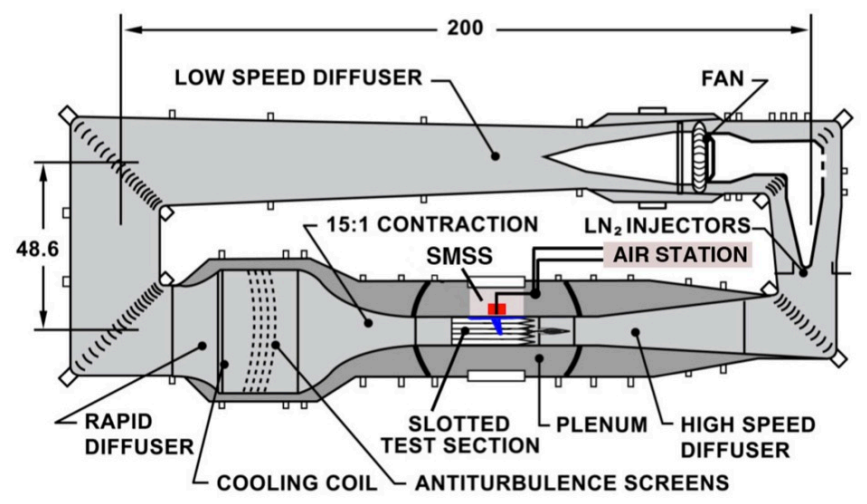

Figure 8. NTF Dual Flow High Pressure Air Delivery System

Semi-span models interface with the SMSS by mechanical joining the model to both the model interface plate, and the top-hat. The top-hat is bolted directly to the semi-span balance; therefore the balance and pressure bellows set are directly linked to each other through the model interface attachment. As a result of the pressure bellows and balance being mechanically linked, any stiffness attributed to the internal bellows pressure can impact the performance by inducing both pressure and momentum tare effects. See Figure 9 below, which shows the internal configuration of the SMSS and all of the important components for the scope of this report. The newly incorporate air lines that are routed through the internal cavity of the balance are joined to the internal turn-table pitching mechanism, which allows the entire system (balance, model, internal instrumentation tube, pressure lines, bellows, etc) to rotate as a single unit. 


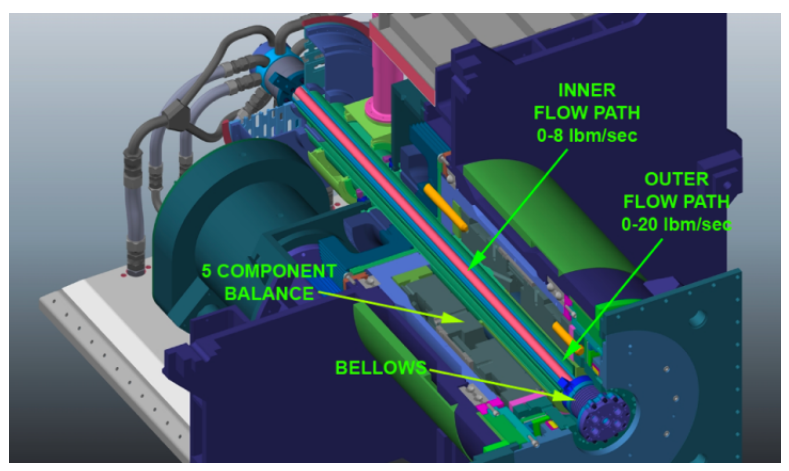

Figure 9. SMSS cutaway showing NTF-117S balance and pressure lines/bellows

Figure 10 below shows the external/internal (high mass-flow/low mass-flow) convoluted bellows, as designed for use with the high pressure air system integrated at the NTF. The bellows are designed with the convolutes under the idea that each behaves as a linear spring under load with minimal stiffness so that under load the interaction of the bellows is minimal on any joined components (specifically to minimize the interaction effect on the stiffness/performance of the balance). The internal bellows fits concentric within the eternal bellows via a slip-fit with o-rings, which are used to seal off the flow between the two legs.
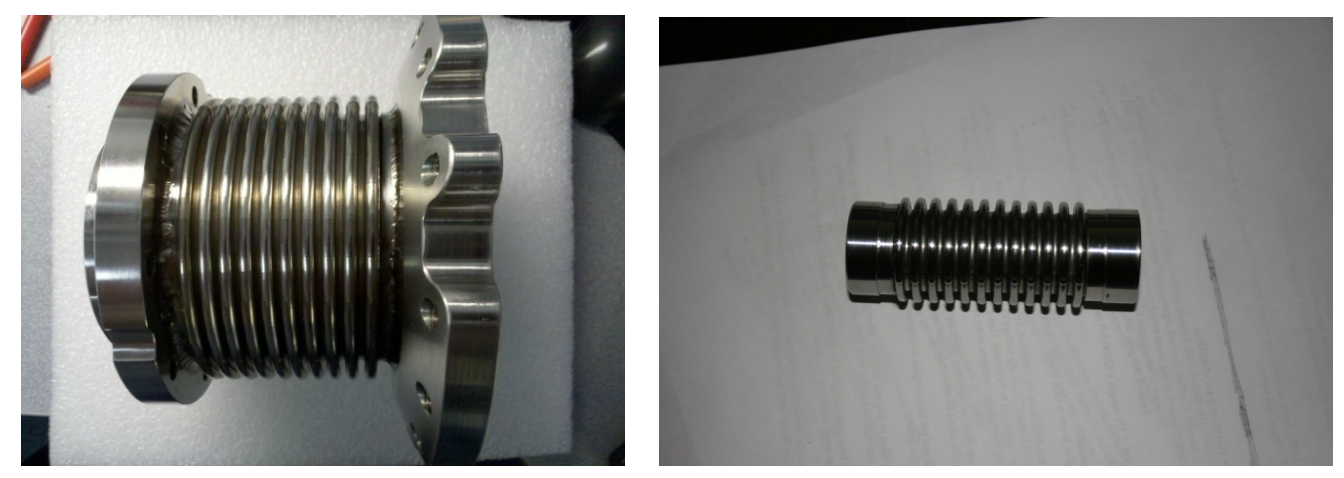

Figure 10. Large External Bellows (left), Small Internal Bellows (right)

The inner and outer bellows have nominal lateral stiffness values of $62 \mathrm{lb} /$ in and $1594 \mathrm{lb} /$ in, respectively. The NTF-117S balance has nominal stiffness values in the axial force and normal force planes of 533,297 lb/in and $6,589,514 \mathrm{lb} / \mathrm{in}$, respectively. Assuming the internal/external bellows act in parallel with each other and the bellows assembly acts in parallel with the balance (as depicted in the spring/mass system in Figure 11), the contribution of the bellows assembly stiffness on the balance is approximately $0.310 \%$ in the axial force plane, and $0.025 \%$ in the normal force plane. Based on these estimates, it was assumed that the addition of these pressure bellows would introduce minimally impact the stiffness and measurement output of the balance component bridges. If necessary, the effects could be calibrated out with a integrated system calibration of the balance/SMSS.

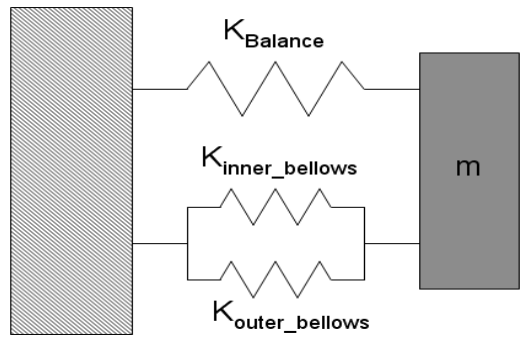

Figure 11. Bellows \& Balance Spring/Mass system

American Institute of Aeronautics and Astronautics 


\section{E. NTF Circulation Control Testing}

An area of research that has shown increased interest in the aircraft research field is that of AFC. AFC research has shown promise in its ability to increase aerodynamic performance of existing conventional aircraft designs, as well as leading to the development of non-conventional aircraft designs. ${ }^{1}$ There are many varieties of AFC, but the one technique that is of interest for upcoming tests at the NTF that will utilize the NTF-117S balance is the area of circulation control. The concept of circulation control works by increasing the velocity of the airflow over the leading edge and/or trailing edge of a wing using high-pressure air that is ejected out of a set of blowing slots. Increasing the momentum of the airflow over the wing by introducing this high-pressure air allows for increasing the resulting lifting capability of the wing, which is critical during both takeoff and landing of any aircraft (research has also shown that circulation control techniques can assist in both drag reduction and simplified maneuvering systems during transonic cruise test conditions ${ }^{13}$ ). The circulation control testing community has been pushing forward building their aerodynamic database, but one area of research that has not been published is circulation control data at actual flight Reynolds numbers, which limits the scalability of the techniques.

The NTF typically utilizes two types of models that utilize blowing, AFC \& Propulsion Airframe Integration (PAI) models. An example of an AFC model that was tested in NTF is the Fundamental Aerodynamic Subsonic Transonic Modular Active Control (FAST-MAC) model shown in Figure 12. This model was used to characterize a circulation control blowing concept that focused on a high-speed jet that blows over the flap region of the wing. The performance results of the FAST-MAC model are described ${ }^{14}$, and the highlighted issues with the blowing characteristics are shown in Figure 12. The cruise performance that is highlighted in the pressure profile data shown in Figure 13 indicates an improvement in drag characteristics for different blowing levels by reattaching the boundary layer and moving the shock aft on the wing. To quantify the drag benefit it will be necessary to validate the pressure data with the pressure tare corrected balance data, which prompted the necessity for performing the work described in detail in this manuscript.

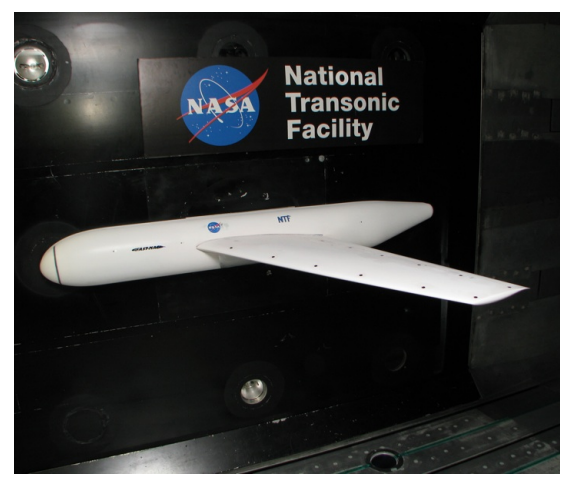

a)

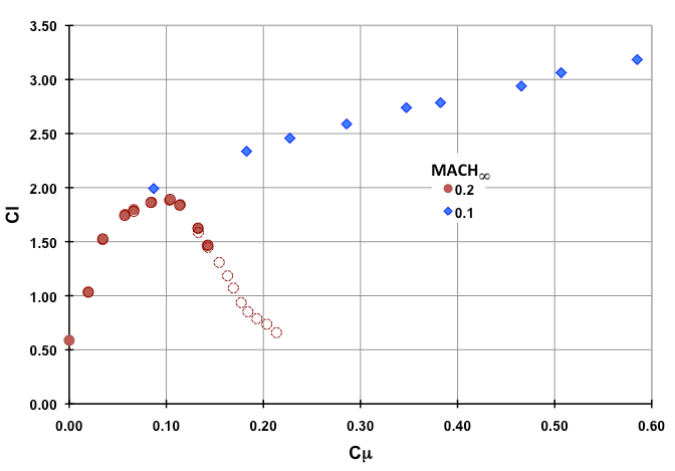

b)

Figure 12. a) The semi-span FAST-MAC model mounted in NTF, b) FAST-MAC high-lift performance at different blowing conditions.

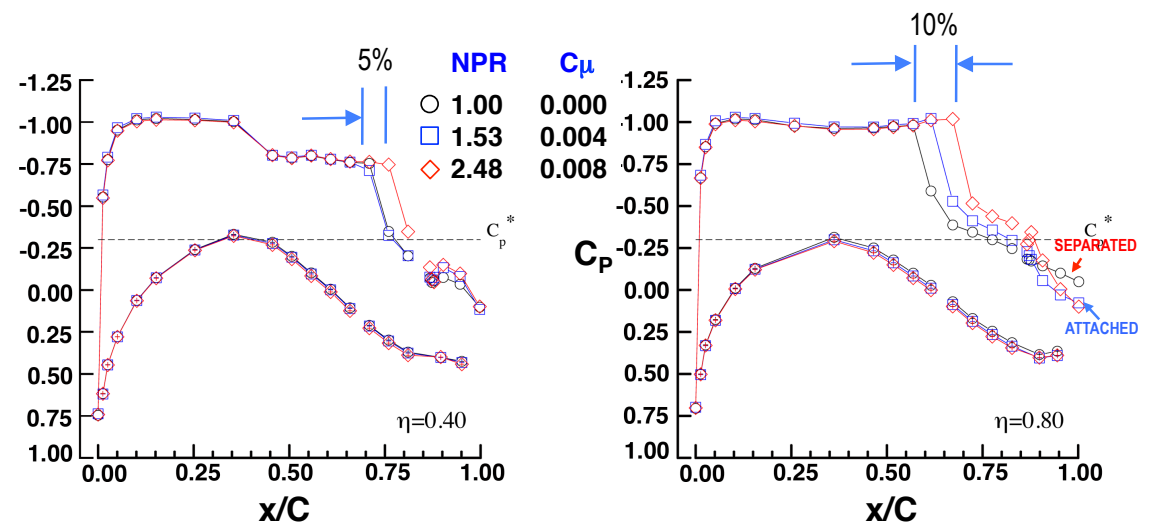

Figure 13. Surface pressure distribution for the cruise configuration of the FAST-MAC model at a Mach number of 0.85 and chord Reynolds number of $30 \times 10^{6}$

10

American Institute of Aeronautics and Astronautics 


\section{NTF-117S Pressure Tare Calibration}

\section{F. Pressure Tare Calibration}

As discussed, the integration of the new air delivery station and the pressure bellows linked to the metric end of the NTF-117S semi-span balance present more independent variables into the system that can impact the performance of the balance. Initial check-loads and test data from several circulation control wind-tunnel tests suggests that the presence of these pressure bellows significantly impact the performance of the balance, requiring that the balance be calibrated as a complete system mounted inside of the SMSS. As shown, the SMSS assembly is quite complex, and any attempt at assembling the balance and simulating the mounting configuration within the SMSS in the balance calibration lab was deemed to be too difficult, and not truly representative of the as-tested configuration. Therefore, it was decided by the research team and the NTF personnel to pursue developing and reinforcing the capability at the facility for performing necessary calibrations on semi-span balances within the SMSS.

\section{G. Pressure Tare Calibration Hardware \& Experimental Design}

For calibration applications, the limitations of the calibration apparatus cannot be ignored when developing an experimental design. The most important phase of an experiment is the pre-experimental planning, where the goals, response variables, and input factors of the experiment are established. Based on the objectives and possible outcomes of an experiment, a successful approach can be formulated. In general, most force balance characterization applications utilize response surface methods, either explicitly or implicitly, where the calibration system is reasonably well-understood and delivering a mathematical calibration model is required. However, in instances where no previous system knowledge is available, a preliminary, factor-screening experiment can be conducted to eliminate unimportant factors before the comprehensive characterization experiment. This approach is known as sequential experimentation and is a strategic and rigorous approach often used in experimental design. ${ }^{15,16}$

During the planning phases of the NTF-117S balance pressure tare calibration, the design team designed and fabricated necessary calibration hardware that allowed for the loading the necessary load combinations during the calibration. The required load combinations needed during the calibration were determined based on the previous load envelopes from both standard semi-span testing at the NTF, and from the recent circulation control testing load envelopes. As with most semi-span balance and semi-span balance calibration systems, there are inherent limitations on what possible load combinations can be applied, due to the physical size of most of the balances. With semi-span testing, there are generally model/wing loading combinations that are not feasible to expect during typical testing (ex. $+\mathrm{NF} / \mathrm{RM},-\mathrm{NF} /+\mathrm{RM},+\mathrm{AF} / \mathrm{YM},-\mathrm{AF} /-\mathrm{YM}$ in combination with each other). The Table of all possible loading combinations, and the cardinal angles is listed in Table 4.

Table 4: Single, 2-Component, 3-Component Feasible Loading Combinations (at cardinal angles)

\begin{tabular}{|c|c|c|c|}
\hline \multicolumn{2}{|c|}{ NF Loadings } & \multicolumn{2}{c|}{ AF Loadings } \\
\hline Load & Orientation & Load & Orientation \\
\hline$+N F$ & $0 \mathrm{deg}$ & $+A F$ & $+90 \mathrm{deg}$ \\
\hline$+N F /+P M$ & $0 \mathrm{deg}$ & $+A F /+P M$ & $+90 \mathrm{deg}$ \\
\hline$+N F /-P M$ & $0 \mathrm{deg}$ & $+A F /-P M$ & $+90 \mathrm{deg}$ \\
\hline$+N F /+R M$ & $0 \mathrm{deg}$ & $+A F /-Y M$ & $+90 \mathrm{deg}$ \\
\hline$+N F /+P M /+R M$ & $0 \mathrm{deg}$ & $+A F /+P M /-Y M$ & $+90 \mathrm{deg}$ \\
\hline$+N F /-P M /+R M$ & $0 \mathrm{deg}$ & $+A F /-P M /-Y M$ & $+90 \mathrm{deg}$ \\
\hline$-N F$ & $180 \mathrm{deg}$ & $-A F$ & $-90 \mathrm{deg}$ \\
\hline$-N F /+P M$ & $180 \mathrm{deg}$ & $-A F /+P M$ & $-90 \mathrm{deg}$ \\
\hline$-N F /-P M$ & $180 \mathrm{deg}$ & $-A F /-P M$ & $-90 \mathrm{deg}$ \\
\hline$-N F /-R M$ & $180 \mathrm{deg}$ & $-A F /+Y M$ & $-90 \mathrm{deg}$ \\
\hline$-N F /+P M /-R M$ & $180 \mathrm{deg}$ & $-A F /+P M /+Y M$ & $-90 \mathrm{deg}$ \\
\hline$-N F /-P M /-R M$ & $180 \mathrm{deg}$ & $-A F /-P M /+Y M$ & $-90 \mathrm{deg}$ \\
\hline
\end{tabular}

Prior to performing the calibration, a series of experiments were run while varying the applied static pressure loadings on the pressure bellows and the loadings on the balance. During these initial experiments it became evident that while varying the applied static pressure on the also affected the internal temperature, which significantly influenced the output of the balance measurement bridges. Similar behavior revealing significant temperature swings on the bellows during initial wind-tunnel tests using the NTF-117S and the convoluted pressure bellows assembly was observed prior to the initial pressure tare calibration of the balance (during the wind-tunnel test the 
range of temperatures observed at the pressure bellows was approximately 15 to $85^{\circ} \mathrm{F}$ ). As a result of these observations, it was decided to add the average bellows temperature sate as an additional calibration factor to the experimental calibration design.

The response variables are the parameters that are measured during an experiment. In force balance calibration, the response variables are the strain-gage outputs and are shown in Table 5. The input factors can be divided into four types: controlled design factors, held-constant factors, uncontrolled factors, and nuisance factors. Controlled design factors are varied during the experiment over specified ranges to study their effects on the response variables. The controlled design factors for this calibration are shown in Table 6. Held-constant and uncontrolled factors are not studied during an experiment because the effects on the responses due to these factors are small and assumed to be negligible. Nuisance factors can be controlled or uncontrolled but their effect on the responses may not be small. While these nuisance factors may not be of interest, it should be recognized that they are present, and precautions should be taken to limit their effect. Blocking is a useful technique in limiting the effect of nuisance factors. ${ }^{15,16}$

Table 5. Calibration Response Variables

\begin{tabular}{|c|c|c|}
\hline Response & Response, Units & Nomenclature \\
\hline $\mathbf{1}$ & Normal Force Bridge Output, $\mathrm{mV} / \mathrm{V}$ & $\mathrm{rNF}$ \\
\hline $\mathbf{2}$ & Axial Force Bridge Output, $\mathrm{mV} / \mathrm{V}$ & $\mathrm{rAF}$ \\
\hline $\mathbf{3}$ & Pitching Moment Bridge Output, $\mathrm{mV} / \mathrm{V}$ & $\mathrm{rPM}$ \\
\hline $\mathbf{4}$ & Rolling Moment Bridge Output, $\mathrm{mV} / \mathrm{V}$ & $\mathrm{rRM}$ \\
\hline $\mathbf{5}$ & Yawing Moment Bridge Output, $\mathrm{mV} / \mathrm{V}$ & $\mathrm{rYM}$ \\
\hline
\end{tabular}

Table 6. Calibration Design Factors

\begin{tabular}{|c|c|c|c|}
\hline Factor & Design Factor & Nomenclature & Range \\
\hline $\mathbf{1}(\mathbf{x} 1)$ & Normal Force & NF & -12000 to $12000 \mathrm{lbs}$ \\
\hline $\mathbf{2}(\mathbf{x} 2)$ & Axial Force & AF & -1800 to $1800 \mathrm{lbs}$ \\
\hline $\mathbf{3 ( x 3 )}$ & Pitching Moment & PM & -90000 to $90000 \mathrm{in}-1 \mathrm{bs}$ \\
\hline $\mathbf{4}(\mathbf{x} 4)$ & Rolling Moment & RM & -669000 to $669000 \mathrm{in}-\mathrm{lbs}$ \\
\hline $\mathbf{5 ( x 5 )}$ & Yawing Moment & YM & -110000 to $110000 \mathrm{in}-\mathrm{lbs}$ \\
\hline $\mathbf{6}(\mathbf{b})$ & Bellows Average Pressure & BelP & 14.7 to $1150 \mathrm{psia}$ \\
\hline $\mathbf{7 ( x 7 )}$ & Bellows Average Temperature & BelT & 15 to $85^{\circ} \mathrm{F}$ \\
\hline
\end{tabular}

Prior to performing the calibration, some preliminary testing was conducted to determine the amount of time required to achieve a stable bellows temperature, while also maintaining a stable temperature level on the balance. During these tests a set of vortex coolers were used to decrease the bellows temperature from ambient to approximately $15^{\circ} \mathrm{F}$. The vortex cooler system used required approximately $8-9$. Due to the significant amount of time required to change the bellows temperature, restricted randomization was employed.

In order to accommodate this practical execution restriction, the bellows temperature was set and held constant while the other six factors were varied randomly. This type of experimental design is known as a split-plot design (SPD). The ideology and concepts of a SPD are attributed to their application in agricultural experiments. ${ }^{17}$ Hardto-change factors were applied over large plots of land and were conveniently called whole plots (WP). The easyto-change factors were crops (and other variables) within a large plot of land and became known as subplots (SP). Temperature was the only WP factor in the calibration while the other factors were subplot factors. By design, every WP in the calibration contained the same subplot design, which is known as a crossed design. These types of SPD's have convenient statistical properties, such as equivalent estimation. However, with any SPD, the error structure must be considered in the analysis. ${ }^{18-20}$

The general form of the mathematical model for a SPD can be written as:

$$
\mathbf{y}=\mathbf{X} \boldsymbol{\beta}+\boldsymbol{\delta}+\boldsymbol{\varepsilon}
$$


Where $\mathbf{y}$ is a $(\mathrm{N} x \mathrm{w})$ matrix of responses, $\mathbf{X}$ is a $(\mathrm{N} x \mathrm{p})$ model matrix, $\boldsymbol{\beta}$ is a $(\mathrm{p} x \mathrm{w})$ matrix of regression coefficients, $\boldsymbol{\delta}$ is a $(\mathrm{N} \mathrm{x} \mathrm{w})$ matrix of random WP errors, $\boldsymbol{\varepsilon}$ is a $(\mathrm{N} \mathrm{x} \mathrm{w})$ matrix of random subplot errors, $\mathrm{N}$ is the total number of runs, $\mathrm{w}$ is the number responses, and $\mathrm{p}$ is the total number of terms in the model (including the intercept). Eq. (2) is a more flexible form of the generic linear model form, which is written as:

$$
\mathbf{y}=\mathbf{X} \boldsymbol{\beta}+\varepsilon
$$

where $\boldsymbol{\varepsilon}$ is a $(\mathrm{N} \mathrm{x} \mathrm{1)} \mathrm{vector} \mathrm{of} \mathrm{random} \mathrm{errors.} \mathrm{Notice} \mathrm{the} \mathrm{difference} \mathrm{between} \mathrm{eq.} \mathrm{(2)} \mathrm{and} \mathrm{(3)} \mathrm{above} \mathrm{is} \mathrm{the} \mathrm{addition} \mathrm{of}$ the $\boldsymbol{\delta}$ matrix for the SPD, which takes into account the random WP errors due to the WP structure of the design and permits correlation and nonhomogeneous variances. Similar balance calibrations at NASA Langley Research Center have been performed to characterize balance system performance where restricted randomization was employed $^{21}$.

In addition to building a SPD, another statistical experimental design concept employed for this calibration was the use of the IV-optimal design ${ }^{15}$. In order to reduce the amount of required time to complete the calibration, it was decided to not perform a standard one factor at a time (OFAT) calibration. In order to optimize the calibration design, and to minimize the number of necessary load points in order to develop the desired mathematical model, it was decided to develop a load schedule employing IV-optimal (integrated-variance optimal) design criteria. Typically in traditional experimental designs where the independent variables are un-constrained a full factorial, fractional factorial or response surface design would be employed allowing for estimating the desired coefficient terms in the mathematical model. In the case where some factor settings are constrained, and it is desired to obtain a minimum data set (due to time constraints) an optimal design can be utilized.

The IV-optimal search algorithm employed seeks to minimize the average prediction variance over the set of points identified from the design, which is powerful in the case of a balance calibration design where the resulting mathematical models will be used for prediction purposes. Given a set of independent variables and ranges for these variables, standard IV-optimal search algorithms will search the entire design space to determine the appropriate factor setting combinations that minimize the prediction variance. Most search algorithms also provide the capability to provide an input list of all possible factor settings combinations, which is then used during the search. This capability is powerful for calibrations and setups where there are physical constraints that restrict the feasible setting combinations. For the calibration of the NTF-117S balance a list of all possible load combinations was developed and input into the search algorithm. Approximately 1100 points were identified in the candidate list.

Based on previous experience with similar semis-span balances, it was decided to construct an experimental design capable of supporting the development of a full quadratic model on all independent variables (linear terms, interaction terms, quadratic terms). The supported 35-term calibration mathematical model for each strain gage output can be characterized as:

$$
y=\beta_{o}+\sum_{i=1}^{7} \beta_{i} x_{i}+\sum_{i=1}^{6} \sum_{j=i+1}^{7} \beta_{i j} x_{i} x_{j}+\sum_{i=1}^{6} \beta_{i i} x_{i}^{2}
$$

Recall from the last term group in eq. (4) above that no pure quadratic term for temperature is included, as the original calibration design only included performing loadings at 2 levels (room and 'cold').

\section{H. Properties of Calibration Design}

Three concepts are typically emphasized and considered during the experimental design process: randomization, replication, and blocking. ${ }^{16}$ Randomization defends against systematic errors in an experiment. Because the runs are executed randomly, any effects due to hysteresis, or other systematic behaviors, are minimized. Replication provides information about the pure experimental error of the response variables. For a given set of factor combinations that is replicated $t$ times, then there are $t-1$ degrees of freedom available to estimate the repeatability, which is an important statistic in any calibration. Finally, as mentioned earlier, blocking is a preventative technique that is used to minimize the effect of any lurking variables in the experiment. Blocks are organized such that orthogonality of the factors is retained in the design matrix. Orthogonality, from the regression perspective, ensures linear independence between terms in the mathematical model. 
When developing the experimental design for characterizing the NTF-117S force balance, several important features were incorporated. These experimental design features were directly related to addressing the specific experimental objectives. Some of the features included in the NTF-117S design were ${ }^{16}$ :

- Sufficient number of data points throughout calibration design space

- Precise model coefficient estimates

- Favorable prediction variance over calibration design space

- Robust calibration

- Execution efficiency

As with any experimental design, the quality of the NTF-117S experimental design was evaluated prior to executing the calibration. The variance inflation factor (VIF) is one metric for assessing the quality of the experimental design. It is a measure of the multicollinearity, or linear dependency, in the regressor variables. The VIF is calculated as:

$$
\operatorname{VIF}(\hat{\beta})=\operatorname{diag}\left[\left(\mathbf{R}^{\prime} \mathbf{R}\right)^{-1}\right]
$$

where $\mathbf{R}$ is the correlation matrix for the design. ${ }^{22}$ For completely orthogonality, $\left(\mathbf{R}^{\prime} \mathbf{R}\right)=\mathrm{I}$, where I is the identity matrix. It is a generally accepted in the balance community to set the upper limit of 5-10 on the VIF. ${ }^{23,24}$ The presence of multicollinearity within a linear regression directly impacts the precision in which regression coefficients can be estimated, so any values of VIF greater than 10 indicates possible flaws within the experimental design.

The standard error of prediction, or prediction variance, is a computed value that provides a estimate on the quality of the predicted responses, based entirely on the experimental design. Given a particular experimental design, the prediction variance is calculated as

$$
\operatorname{Var}\left[\hat{y}\left(x_{0}\right)\right]=\sigma^{2}\left(x_{0}^{\prime}\left(\mathbf{X}^{\prime} \mathbf{X}\right)^{-1} \mathbf{x}_{0}\right)
$$

where $\mathrm{x}_{0}$ represents the location of a point within the design space. Essentially, the variance is a scale factor for the prediction variance. For a SPD, Eq. 6 becomes

$$
\operatorname{Var}\left[\hat{y}\left(x_{0}\right)\right]=\mathbf{x}_{0}^{\prime}\left(\mathbf{X}^{\prime} \boldsymbol{\Sigma}^{-1} \mathbf{X}\right)^{-1} \mathbf{x}_{0}
$$

Response surface plots are an efficient method to check the prediction variance of a design. Ideally, the surface should be flat, which signifies constant prediction properties across the entire design space of the balance.

Table 7 shows the identified loading combinations, with a descriptor in the right hand column distinguishing points used to build the calibration models (design points) and points used to validate the models (confirmation points). A total of 53 points were identified ( 28 points used to build models, 5 to estimate LOF, 15 replicates for estimation of pure error, and 5 center points to test/detect curvature at the center of the design space). A unique set of confirmation points were selected for each WP by selecting points from the candidate list not selected to build the calibration models. In Table 7 confirmation run points 54 thru 64 were performed during the first WP at room temperature, and used for model validation purposes.

While the initial load schedule was designed using all achievable load points as a candidate set for the IVoptimal algorithms to generate the required number of loadings required for an optimal calibration, it was decided to slightly augment the design with additional points for added benefit. As will be discussed in the calibration execution section, instead of simply running the load schedule in Table 7 for each WP, it was decided for the first calibration to transform each run identified in Table 7 into a traditional incremental load series performed during most traditional balance calibrations. It was decided to pursue this course for the primary reason that since a significant amount of setup time is required to get to each set point (applied pressure, temperature, manually moving weight basket to each position) it was advantageous to acquire additional data points for the calibration, and no significant increase in time required to collect those additional data points. It should be noted that there implications 
with performing each load series in this manner, as there is a certain level of correlation that will exist between runs purely attributed to the sequential nature of the pressurization/applied loadings in each series.

Table 7. Calibration Load Schedule Design (Room Temperature Only)

\begin{tabular}{|c|c|c|c|c|c|c|c|}
\hline Run Point & NF, x1 (lb) & AF, x2 (Ib) & PM, x3 (in-lb) & RM, x4 (in-lb) & YM, x5 (in-lb) & Pressure, x6 (psi) & Point Type \\
\hline 1 & 866 & 75 & 0 & 56001 & -55750 & 1150 & design \\
\hline 2 & 0 & 40 & 0 & 4563 & -275 & 575 & design \\
\hline 3 & 866 & 500 & 0 & 56001 & -55750 & 575 & design \\
\hline 4 & 866 & 75 & -7500 & 56001 & -55750 & 1150 & design \\
\hline 5 & 866 & 75 & 0 & 56001 & -55750 & 1150 & design \\
\hline 6 & 966 & -259 & 0 & 0 & 0 & 575 & design \\
\hline 7 & -3000 & 0 & -22500 & -168002 & 0 & 1150 & design \\
\hline 8 & 1992 & 174 & -15000 & 112001 & -111500 & 0 & design \\
\hline 9 & 1992 & 174 & 0 & 112001 & -111500 & 1150 & design \\
\hline 10 & 1932 & 78 & -15000 & 112001 & -111500 & 0 & design \\
\hline 11 & -996 & 87 & 7500 & -56001 & -55750 & 0 & design \\
\hline 12 & 11954 & -1046 & -90000 & 0 & 0 & 0 & design \\
\hline 13 & -866 & -75 & 0 & -56001 & 55750 & 1150 & design \\
\hline 14 & 866 & 75 & 0 & 56001 & -55750 & 1150 & design \\
\hline 15 & -87 & 149 & 7500 & 56001 & 55750 & 575 & design \\
\hline 16 & 1932 & -78 & 0 & 112001 & 111500 & ds & design \\
\hline 17 & -12000 & 0 & 0 & -672009 & 0 & 1150 & design \\
\hline 18 & 87 & 149 & -7500 & 56001 & 55750 & 0 & design \\
\hline 19 & 866 & 75 & 0 & 56001 & -55750 & 1150 & design \\
\hline 20 & 0 & 40 & 0 & 4563 & -275 & 575 & design \\
\hline 21 & 1932 & 78 & -15000 & 112001 & -111500 & 0 & design \\
\hline 22 & 3000 & 0 & -22500 & 168002 & 0 & 1150 & design \\
\hline 23 & 0 & 40 & 0 & 4563 & -275 & 575 & design \\
\hline 24 & -866 & 500 & 7500 & 0 & 0 & 0 & design \\
\hline 25 & 1992 & 174 & -15000 & 112001 & -111500 & 0 & design \\
\hline 26 & 1992 & 174 & 0 & 112001 & -111500 & 1150 & design \\
\hline 27 & -866 & -75 & 0 & -56001 & 55750 & 1150 & design \\
\hline 28 & -5977 & 523 & 45000 & 0 & 0 & 575 & design \\
\hline 29 & 866 & 75 & 7500 & 0 & 0 & 1150 & design \\
\hline 30 & 966 & -259 & 7500 & 56001 & 55750 & 0 & design \\
\hline 31 & -1932 & 78 & 15000 & -112001 & -111500 & 1150 & design \\
\hline 32 & -12000 & 0 & 90000 & 0 & 0 & 575 & design \\
\hline 33 & 866 & 75 & 7500 & 0 & 0 & 1150 & design \\
\hline 34 & 9000 & 0 & 67500 & 0 & 0 & 0 & design \\
\hline 35 & 866 & 75 & -7500 & 56001 & -55750 & 1150 & design \\
\hline 36 & 1992 & 174 & -15000 & 112001 & -111500 & 0 & design \\
\hline 37 & -866 & 75 & -7500 & 0 & 0 & 1150 & design \\
\hline 38 & 0 & -800 & 6000 & 0 & 0 & 1150 & design \\
\hline 39 & 866 & 500 & 0 & 56001 & -55750 & 575 & design \\
\hline 40 & -87 & -996 & -7500 & 56001 & 55750 & 1150 & design \\
\hline 41 & 1932 & 78 & -15000 & 112001 & -111500 & 0 & design \\
\hline 42 & 866 & 75 & 0 & 56001 & -55750 & 1150 & design \\
\hline 43 & -866 & 75 & -7500 & 0 & 0 & 1150 & design \\
\hline 44 & -12000 & 0 & -90000 & -672009 & 0 & 0 & design \\
\hline 45 & 0 & 40 & 0 & 4563 & -275 & 575 & design \\
\hline 46 & 0 & 40 & 0 & 4563 & -275 & 575 & design \\
\hline 47 & -866 & -75 & 0 & -56001 & 55750 & 1150 & design \\
\hline 48 & -5977 & 523 & 45000 & 0 & 0 & 0 & design \\
\hline 49 & 866 & 75 & 7500 & 0 & 0 & 1150 & design \\
\hline 50 & -12000 & 0 & -90000 & 0 & 0 & 575 & design \\
\hline 51 & 12000 & 0 & 0 & 672009 & 0 & 575 & design \\
\hline 52 & -12000 & 0 & 90000 & -672009 & 0 & 0 & design \\
\hline 53 & 5977 & -523 & 45000 & 0 & 0 & 575 & design \\
\hline 54 & 0 & -800 & 0 & 0 & 44600 & 0 & confirmation \\
\hline 55 & 0 & -800 & -6000 & 0 & 44600 & 350 & confirmation \\
\hline 56 & 0 & -800 & 6000 & 0 & 44600 & 0 & confirmation \\
\hline 57 & -87 & -796 & 6000 & -44600 & 44600 & 0 & confirmation \\
\hline 58 & -70 & -796 & -6000 & -44600 & 44600 & 150 & confirmation \\
\hline 59 & -12000 & 0 & -90000 & -669000 & 0 & 900 & confirmation \\
\hline 60 & -5977 & 523 & -45000 & 0 & 0 & 800 & confirmation \\
\hline 61 & 87 & 996 & 7500 & 44600 & 44600 & 0 & confirmation \\
\hline 62 & 939 & 342 & -7500 & 55750 & -55750 & 350 & confirmation \\
\hline 63 & 1992 & 174 & -15000 & 0 & 0 & 0 & confirmation \\
\hline 64 & 5977 & -523 & -45000 & 0 & 0 & 1150 & confirmation \\
\hline
\end{tabular}

15

American Institute of Aeronautics and Astronautics 
An example of an as-run unpressurized and pressurized load series are shown in Table 8. Notice that in the unpressurized load series there is start/end un-loaded state, and the middle increment is the full load combination based on the run/point identified from the optimal design defined in Table 7. The pressurized style load series have an initial un-loaded state, the static pressure set point is then applied to the inner/outer bellows while the balance is not loaded with any force/moments, then after the static pressure settles out the balance is physically loaded to achieve the desired resultant forces/moments (as identified in the optimal load schedule in Table 7). These additional data points aided in simplifying the data analysis procedures (simplified the weight tare correction computations, since each series has an un-loaded reference state), and also yielded additional data/information during this initial exploratory calibration, which aided in better assessment of the system calibration. It should be noted that the augmentation of the optimal design to incorporate each load into a incremental series as identified above require minimal additional effort/time, since the majority of the required time for each load goes into manually moving the weight basket from point to point in between each different load combination.

Table 8: Example As-Run Load Series (Unpressurized \& Pressurized)

\begin{tabular}{|c|c|c|c|c|c|c|c|c|}
\hline \multirow{5}{*}{ 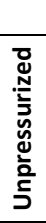 } & & \multicolumn{5}{|c|}{ Resultant Forces/Moments } & \multirow[b]{2}{*}{$\begin{array}{c}\text { BelP_Low } \\
\text { (psi) }\end{array}$} & \multirow[b]{2}{*}{$\begin{array}{c}\text { BelP_High } \\
\text { (psi) }\end{array}$} \\
\hline & Applied Load & NF (lb) & $\mathrm{AF}(\mathrm{lb})$ & PM (in-lb) & RM (in-lb) & YM (in-lb) & & \\
\hline & 0 & 0 & 0 & 0 & 0 & 0 & 0 & 0 \\
\hline & 9000 & 8966 & -784 & -67500 & 0 & 0 & 0 & 0 \\
\hline & 0 & 0 & 0 & 0 & 0 & 0 & 0 & 0 \\
\hline \multirow{5}{*}{ 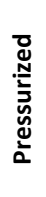 } & 0 & 0 & 0 & 0 & 0 & 0 & 0 & 0 \\
\hline & 0 & 0 & 0 & 0 & 0 & 0 & 1150 & 1150 \\
\hline & 6000 & 5977 & -523 & -45000 & 0 & 0 & 1150 & 1150 \\
\hline & 0 & 0 & 0 & 0 & 0 & 0 & 1150 & 1150 \\
\hline & 0 & 0 & 0 & 0 & 0 & 0 & 0 & 0 \\
\hline
\end{tabular}

Table 9 contains detail on the number of loadings performed during each WP or temperature setting. Each WP contained a set number of calibration runs, used for building the models, and a certain number of confirmation points used for model validation purposes. At the end of the calibration a set of loadings were performed at a midlevel temperature of approximately $45^{\circ} \mathrm{F}$, and these data were used to test the models for prediction capability purposes at a temperature level not used during the calibration. Note that WP1 contains significantly more calibration runs than the other WP's, this was due to the fact that during the loadings a certain set of single component loadings were performed at each cardinal angle, to establish a set of baseline performance criteria for the simplest possible loading conditions.

Table 9: Execution of Experimental Design

\begin{tabular}{|c|c|c|c|c|c|c|}
\hline & WP 1 & WP 2 & WP 3 & WP 3 & $\begin{array}{c}\text { Mid-Temperature } \\
\text { Confirmation Runs }\end{array}$ & Total \\
\hline Calibration Runs & 278 & 213 & 221 & 215 & 0 & 927 \\
\hline Confirmation Runs & 45 & 41 & 27 & 37 & 38 & 188 \\
\hline Total Runs $^{\circ}$ & 323 & 254 & 248 & 252 & 38 & 1115 \\
\hline Temperature, $^{\circ} \mathbf{F}$ & 77 & 20 & 77 & 20 & 45 & - \\
\hline Pressure Levels & 3 & 3 & 3 & 3 & 3 & - \\
\hline
\end{tabular}

\section{Calibration Hardware Design \& SMSS Configuration}

The design of the load schedule and the mechanical design of the calibration hardware used to calibrate the balance were conducted in parallel. During this process all of the possible load combinations (as shown in Table 4) were determined based on the feasible loading conditions expected during testing, and then the hardware was designed to set the desired loads. Due to the high load capacity of the balance, it was critical to design the calibration system to provide the correct load points, while keeping in mind the fixture needed to have sufficient stiffness in order to minimize deflections under load. 
The calibration fixture was designed to be as lightweight yet stiff as possible, and it incorporated a bearing/bushing that allowed the fixture to rotate relative to the balance. The addition of this bushing design into the fixture allows the fixture to stay vertically aligned with gravity, while the balance is pitched inside of the SMSS. This feature allows the balance to be pitched to any desired angle during the calibration, which is extremely desirable in that it is best to calibrate the balance where each of the measurement components are loaded simultaneously at various factor settings that lie within the design space of the balance. The ability to apply multicomponent loadings to the balance allows the ability to design a more efficient calibration load schedule that allows for exploring the balances design space, and provides the ability to estimate the interaction terms with more power.

Several angle measurement system (AMS) packages were integrated into the design of the fixture at different locations, which were used to measure and correct for any deflections and relative slipping between the balance and the fixture. In order to secure the fixture to the balance a friction joint was used to lock the fixture to the metric end of the balance. The calibration fixture is shown in Figure 14. Figures 15 thru 16 show the calibration fixture mounted to the balance, where the balance is mounted inside of the SMSS. The first 3-axis AMS package was mounted to a flat on the top of the bushing shaft (used to measure the balance metric end pitch/roll angles). The second 3-axis AMS was mounted to the upper flat surface on the vertical plate, and was used to measure any relative pitch slip between the fixture and the metric end of the balance. The last 3-axis AMS was mounted at different locations on the base of the fixture (used to measure deflections at the point of load application, to allow for correcting the applied loads for any deflections that cause the load point to move from the nominal position).

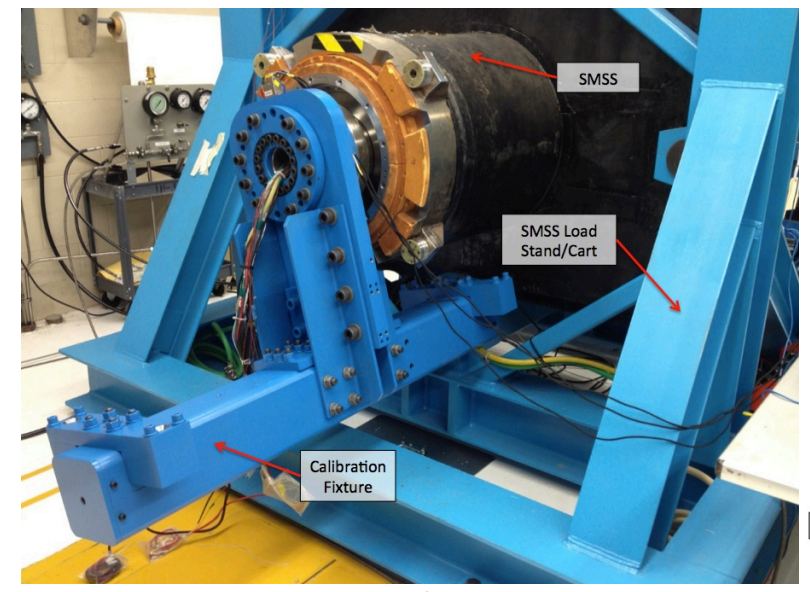

a)

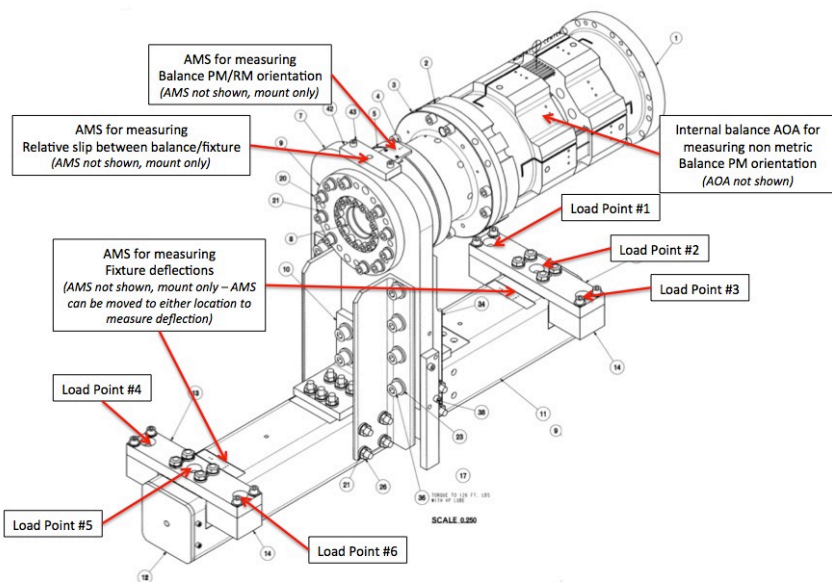

b)

Figure 14. Calibration Fixture, a) Mounted to Balance in the stand, b) Schematic

Figure 13 shows the configuration of the calibration load fixture, the locations of the AMS packages, and identified the locations of the 6 load points. Load points 1 thru 3 are located at the balance moment center (BMC), where point 2 is directly at $\mathrm{BMC}$, points 1 and 3 are forward and aft of BMC, respectively. Applying a load at point 2 , with the balance in the $-\mathrm{NF}$ position (-NF down) would result in a 'pure' $-\mathrm{NF}$ being applied to the balance. Applying a load at point 1 in the -NF position would result in a -NF/-PM load combination (point 3 would result in a $-\mathrm{NF} / \mathrm{PM}$ load combination). Load points 3 thru 6 are located at a station offset from BMC, providing the other possible combinations with the balance in the $-\mathrm{NF}$ orientation (point $4=-\mathrm{NF} /-\mathrm{PM} /-\mathrm{RM}$, point $5=-\mathrm{NF} /-\mathrm{RM}$, point $6=-\mathrm{NF} /+\mathrm{PM} /-\mathrm{RM})$. By rotating the balance through $+/-180$ degrees, nearly any possible single or multicomponent load combination can be achieved, except for combinations previously discussed.

The NTF SMSS is a highly integrated unit, which is composed of several sub-systems, listed below which are used during all semi-span testing at the facility.

1. External Semi-Span balance

2. Interface with high-pressure air station, and all routing of high-pressure air to semi-span models

3. Instrumentation interface between test model and facility DAS

4. Pitching mechanism used to pitch model during testing 
5. Balance heater controls \& recirculation system for controlling balance temperatures at elevated temperatures (approximately $100^{\circ} \mathrm{F}$ ) during testing in tunnel

As seen in Figure 15, the high-pressure air is routed into the rear of the SMSS, down the center of the mechanism, through the balance and interfaces with the pressure bellows assembly forward of the balance. During testing and calibration of the balance, a model/calibration interface plate is fastened to the top-hat interface, and the bellows are then fastened to this model/calibration interface plate. As a result of this assembly configuration, any stiffness imparted by the bellows (due to pressurization) will directly be seen by the balance, therefore requiring the balance to be calibrated as a system assembly for proper characterization.

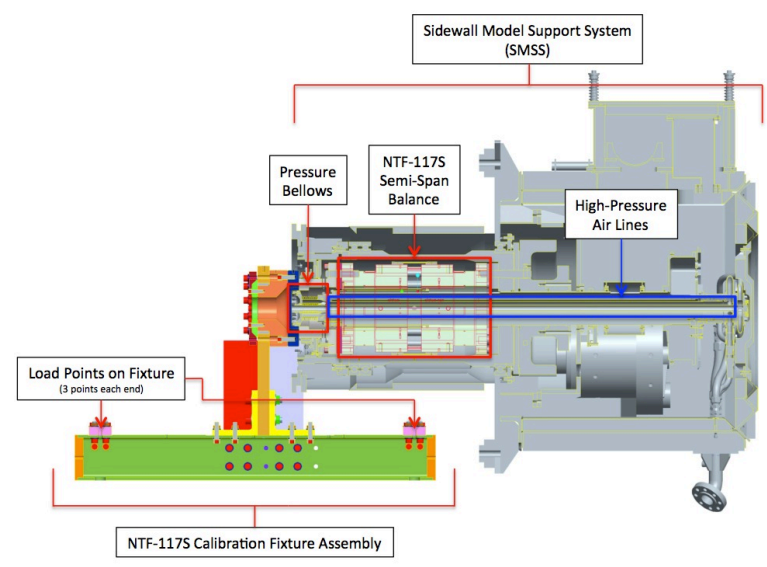

Figure 15: Cross Section of SMSS and Balance Calibration Assembly (SMSS stand not shown)

Figure 16 shows a close-up cross-section view of the balance/calibration fixture interface, showing the highly complex configuration of the different internal components of the SMSS, and how the different component inside the SMSS interact with the balance during operational use. While the inner/outer pressure bellows were originally designed with convoluted sections to minimize introduction of any stiffness into the system, it is clear that the bellows are an integrated part of the system, and any non-ideal behavior of the bellows under load (from balance or applied pressure) can directly influence how the balance behaves. There are multiple joints in between the grounded end of the balance and the calibration fixture, each of which are designed to minimize any relative motion between the two joined components.

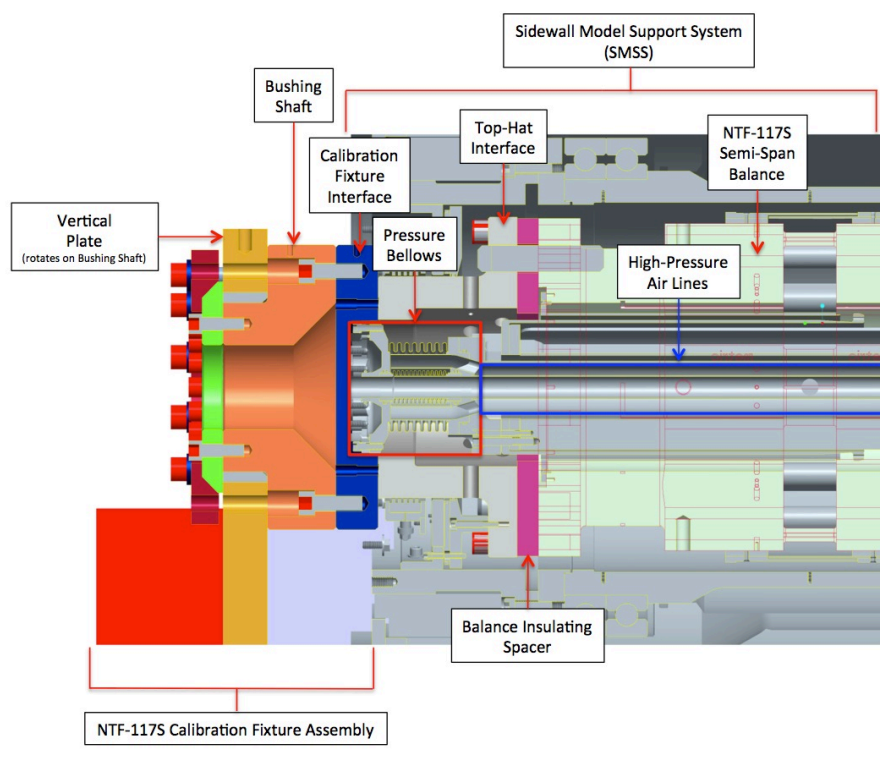

Figure 16: Cross Section of SMSS and Balance Calibration Assembly

18

American Institute of Aeronautics and Astronautics 


\section{J. Calibration Setup \& Execution}

As discussed, the calibration was broken into WP's due to the fact that the time required to reach a desired point takes 8-12 hours. While at each WP temperature, the various load combinations for identified in Table 7 were completed by varying the angle of the balance, and the applied forces/moments/bellows pressures. In order to physically apply the forces/moments to the balance, it was required to move a weight stack to different points on the calibration fixture (to be described in the next section discussing the calibration fixture design), with the weight stack containing 12,000 lb of lead weights. Moving the 12,000 lb weight stack from one position to another requires manually pushing it, requiring several technicians.

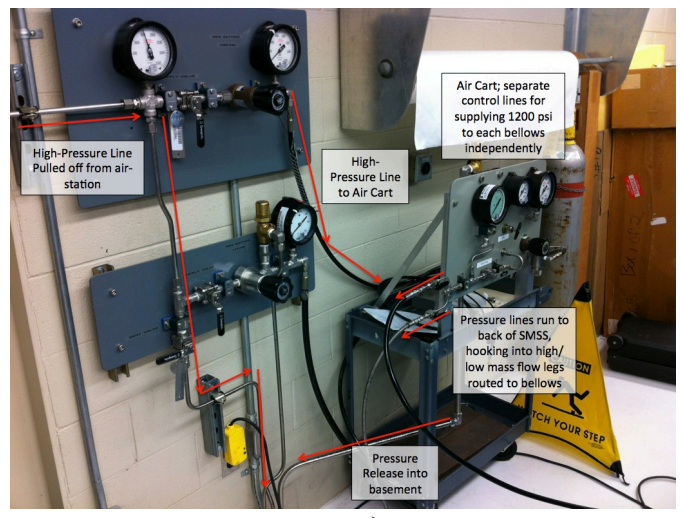

a)

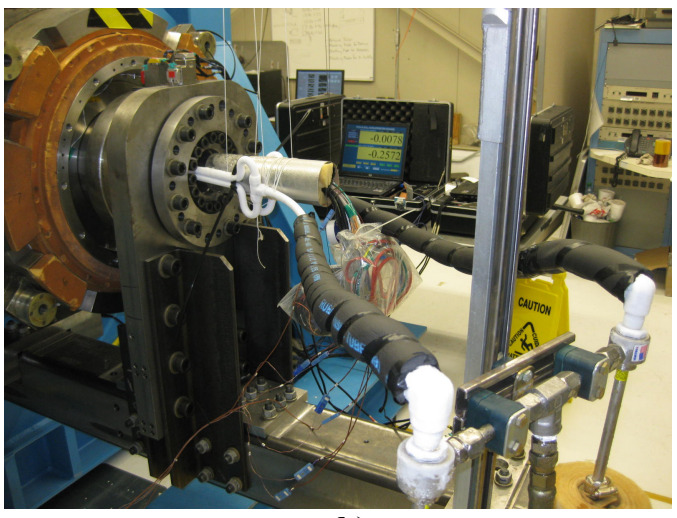

b)

Figure 17. Model Preparation Area, a) Air Cart Configuration, b) Vortex Cooler Configuration

In order to set the applied static pressure to the internal bellows, the NTF routed a high-pressure airline from the air-station in to the MPA where a separation high-pressure air cart was designed with various pressure relief valves, gauges, and valves to allow for independently applying desired pressures to both the pressure bellows and vortex coolers (used to set/control bellows temperatures). Figure 17 shows the high-pressure air-cart configuration developed in the MPA, allowing for localized pressure changes during the calibration, and allowing for independently varying the applied static pressure in each bellows. In order to achieve the desired bellows temperature setting, the facility incorporated a duel vortex cooler/tube system, which uses shop air pressure to drive the vortex coolers/tubes. The vortex coolers are mechanical devices that separate an incoming compressed gas (in our case shop air) into hot and cold air streams.

The 'cold' air side of the vortex cooler was routed through instrument passages in the fixture/top-hat interface assembly, and into the internal cavity of the balance where the bellows are located. The lines were routed such that the 'cold' air lines from the vortex coolers were directed at the flange of the bellows directly fastened to the inner surface of the top-hat interface (where the bellows are capped off), allowing thermal conduction from one side to the other, thus cooling the bellows. The conduction of the temperature through this assembly resulted in a longer duration for achieving set points, but resulted in a more stable temperature setting once achieved. Prior to installation of the calibration fixture the flanges and outer convolutes of the outer bellows were instrumented with a series of thermocouples, allowing for the temperature state of the outer bellows to be monitored/recorded during calibration.

Prior to performing the calibration bounds were set on the set points for the bellows pressure and bellows temperature, in order to establish an acceptable range in which to target the defined set points. The bellows pressure were measured at the back of the SMSS, where the high-pressure air lines from the air cart are connected into the air supply flanges. The pressure sensors have a measurement accuracy of $+/-0.5 \mathrm{psia}$, and the set point acceptable range during the calibration was set to $+/-5$ psia (opened up range to account for initial drift during settling time). A total of seven type $\mathrm{K}$ thermocouples were instrumented on the bellows (three on the flange, 4 on the convolute section), with each having a nominal measurement accuracy of $+/-0.5^{\circ} \mathrm{F}$. The desired range of the bellows thermocouple setting once the set point was reached was $+/-2^{\circ} \mathrm{F}$. During the course of the calibration it was observed that the bellows temperature was unstable when under the influence of applying a static pressure to the bellows. 
When pressurizing the bellows to any pressure level above approximately 200 psia, it was observed that the temperature state of the bellows (both convolutes and flange temperatures) increased outside of the nominal noise floor, and the magnitude of the temperature 'spike' varied between all the instrumented locations. Typically this initial temperature spike due to the bellows pressurization was on the order of $1-4^{\circ} \mathrm{F}$ when the bellows was initially at room temperature, while the spike was on the order of $3-12^{\circ} \mathrm{F}$ when the bellows was initially at the 'cold' temperature set points. This observation is critical, as it required varying amounts of time between data collection depending on the temperature state of the bellows. While calibrating the system at room temperature, once the bellows was pressurized to its set point there was a period of 10-15 minutes required for the bellows temperature to stabilize to a point where the initial gradient of the temperature spike leveled out. The time required for the bellows temperature to stabilize when the bellows was initially at a 'cold' state required 20-30 minutes between the initial pressurization and the start of data collection.
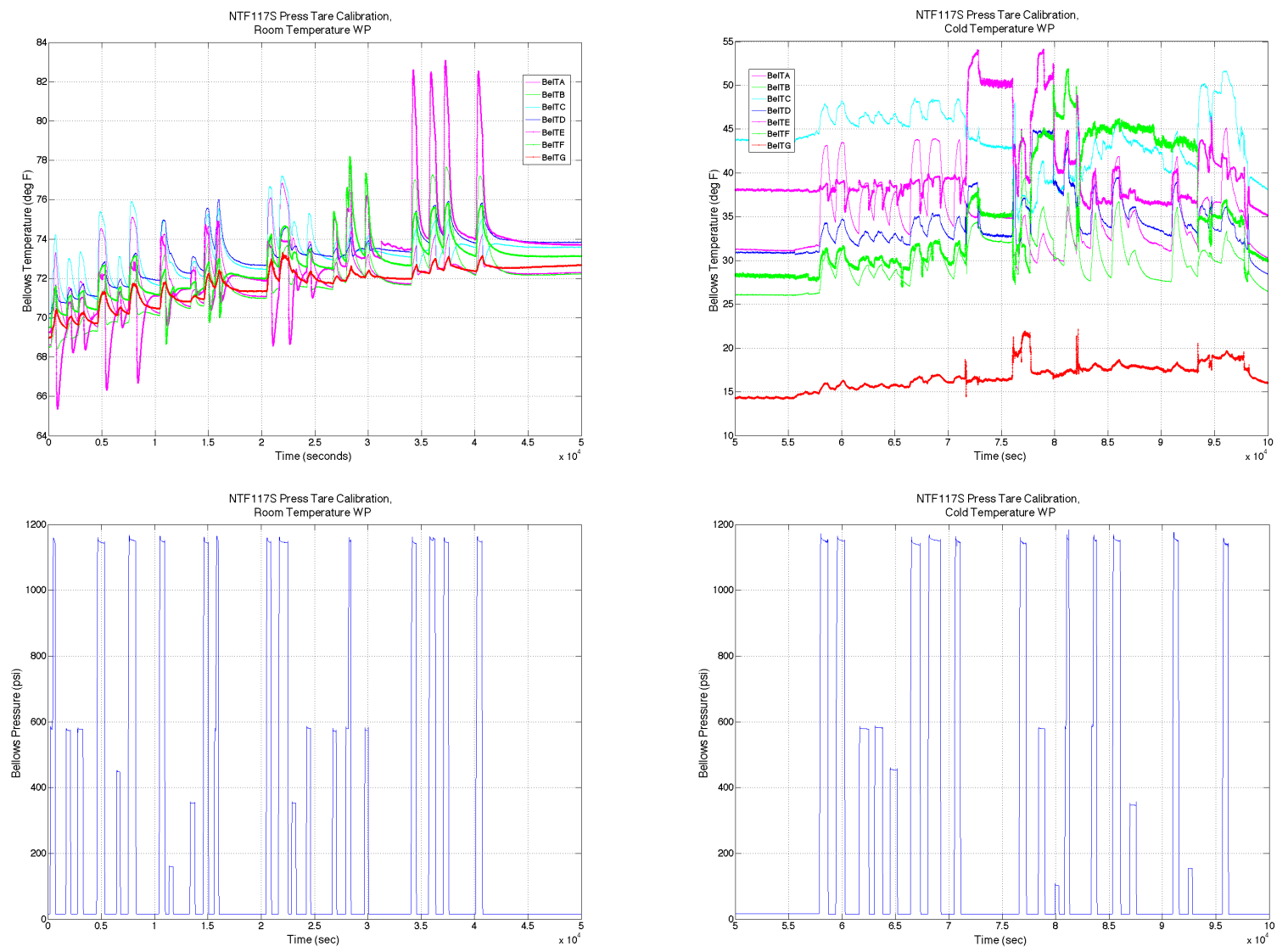

a)

Figure 18. BelP \& BelT time-history plots for a) Room \& b) Cold Temperature Loadings

The temperature instability of the bellows while pressurizing the bellows required more time required per data point collected, and also introduced the realization that after allowing the bellows temperature to stabilize it never returned back to its initial start point (the temperature state observed prior to pressurizing the bellows). Since the calibration models are being developed as continuous functions, the critical feature is that the actual factor settings be measured, which was achieved during this calibration. The only complication presented by this temperature instability is the fact that the replicated load points within the design are never going to truly be replicates. While the measured factor settings (primarily the average bellows temperature) are relatively close within the replicated settings, they will have a magnitude of induced error due to the fact that the temperature can not be controlled to the point where the set point can be accurately set for these replicated points. Figure 18 plots out the applied bellows pressures and temperature measurements of the bellows during both room and 'cold' temperature loadings during the calibration. As seen from the figure, every time time the bellows is pressurized each of the temperature sensors on the bellows sees an immediate spike, and then an exponential decay. The nature of the bellows to not return back 
to its original temperature state is clearly seen in Figure 18a, as the temperature state trends such that the bellows heats up over the course of the calibration.

\section{K. Pressure Tare Calibration Results \& Analysis}

At the conclusion of the calibration the collected responses (measurement bridge outputs) and the theoretical applied loads were tabulated and analyzed. Typical analysis for most balance calibrations requires computing the tare weight contribution during each load point in the calibration (this is done through an iterative process), and then statistically analyzing the tare corrected loads and responses for each calibration load. The analysis consists of performing statistical tests on the significance of each regression coefficient in the desired model. It should be noted here that since the experimental load schedule design was constructed as a nearly crossed design, it is assumed that the equivalency property holds and the ordinary least squares (OLS) approach is appropriate for estimating the model coefficients for each response. While this is true, it should be noted that since the experimental design was constructed as a SPD design, applying model reduction techniques in conjunction with OLS does not take into consideration the estimation of the correlation among the observations/responses. For this initial assessment model reduction was employed while using OLS, assuming the data sets as complete randomized design (assuming no restriction on the randomization), and the consequences of applying this method were assumed to be minimal when quoting the final back-computed residual accuracies. The author acknowledges and accepts the consequences employed for this initial assessment.

Table 10 below shows the statistically significant model terms remaining after the analysis of variance (ANOVA) and removing any non-significant terms (level of significant, alpha $=0.01$ for this analysis). The terms remaining in each model after the model reduction are indicated by 1's in the table, and 0's represent all nonsignificant terms. As observed from Table 10, the intercept terms were included for each model. Since the separate WP's were combined, the final models include linear and two-factor combinations involving the temperature factor for each measurement response.

Table 10: Statistically Significant Model Terms $(0=$ not significant, $1=$ significant $)$

\begin{tabular}{|c|c|c|c|c|c|}
\hline GAGE_OUT_NAME & rNF & rPM & rYM & rRM & rAF \\
\hline INTERCEPT & 1 & 1 & 1 & 1 & 1 \\
\hline NF (x1) & 1 & 1 & 1 & 1 & 1 \\
\hline PM (x3) & 1 & 1 & 1 & 1 & 1 \\
\hline YM (x5) & 0 & 1 & 1 & 1 & 1 \\
\hline RM (x4) & 1 & 1 & 1 & 1 & 1 \\
\hline $\mathbf{A F}(\mathbf{x 2})$ & 1 & 1 & 1 & $\mathbf{0}$ & 1 \\
\hline BelP (x6) & 1 & 1 & 1 & 1 & 1 \\
\hline BelT (x7) & 1 & 1 & 1 & 1 & 1 \\
\hline NF*NF & $\mathbf{0}$ & 1 & $\mathbf{0}$ & $\mathbf{0}$ & $\mathbf{0}$ \\
\hline $\mathbf{P M} * \mathbf{P M}$ & 1 & $\mathbf{0}$ & 1 & 1 & $\mathbf{0}$ \\
\hline $\mathbf{Y M}$ :YM & $\mathbf{0}$ & $\mathbf{0}$ & 1 & 1 & $\mathbf{0}$ \\
\hline $\mathbf{R M} \mathbf{R M}$ & $\mathbf{0}$ & $\mathbf{0}$ & $\mathbf{0}$ & 1 & $\mathbf{0}$ \\
\hline$A F * A F$ & $\mathbf{0}$ & $\mathbf{0}$ & $\mathbf{0}$ & 0 & $\mathbf{0}$ \\
\hline BelP*BelP & 1 & 0 & 1 & 0 & 1 \\
\hline NF*PM & 0 & 1 & 1 & 0 & 1 \\
\hline $\mathrm{NF}^{*} \mathbf{Y M}$ & 0 & 0 & 0 & 0 & 0 \\
\hline NF*RM & $\mathbf{0}$ & 0 & 0 & 0 & $\mathbf{0}$ \\
\hline $\mathrm{NF}^{*} \mathbf{A F}$ & 0 & 0 & 1 & 0 & 0 \\
\hline NF*BelP & 1 & 0 & 1 & 0 & 1 \\
\hline NF*BelT & $\mathbf{0}$ & 1 & 1 & 1 & 1 \\
\hline $\mathbf{P M} * \mathbf{Y M}$ & 0 & 0 & 0 & 0 & 0 \\
\hline PM*RM & 0 & 1 & 1 & 0 & 1 \\
\hline $\mathbf{P M}$ *AF & $\mathbf{0}$ & $\mathbf{0}$ & $\mathbf{0}$ & $\mathbf{0}$ & $\mathbf{0}$ \\
\hline PM*BelP & 0 & 0 & 0 & 0 & 1 \\
\hline PM*BelT & 1 & 0 & 0 & 0 & 0 \\
\hline $\mathbf{Y M}$ *RM & $\mathbf{0}$ & $\mathbf{0}$ & $\mathbf{0}$ & $\mathbf{0}$ & $\mathbf{0}$ \\
\hline $\mathbf{Y M} * \mathbf{A F}$ & 0 & 0 & 0 & 0 & 1 \\
\hline YM*BelP & 0 & 0 & 0 & 1 & 0 \\
\hline YM*BelT & $\mathbf{0}$ & $\mathbf{0}$ & $\mathbf{0}$ & 1 & $\mathbf{0}$ \\
\hline $\mathbf{R M} * \mathbf{A F}$ & 0 & 0 & 1 & 0 & 0 \\
\hline RM*BelP & 0 & 0 & 1 & 1 & 0 \\
\hline RM*BelT & 0 & 0 & 0 & 0 & 0 \\
\hline AF*BelP & 0 & 0 & 1 & 0 & 1 \\
\hline AF* BelT & 1 & 1 & 1 & 0 & 1 \\
\hline BelP*BelT & 0 & 0 & 1 & 0 & 1 \\
\hline
\end{tabular}


Table 11 below reveals the final regression coefficient matrix (RCM) after performing the analysis. The coefficients are shown in engineering units, not in a coded form. This RCM expresses the bridge outputs as functions of the applied factor settings ${ }^{25}$. This global regression is performed using the applied loads (factors) as the independent variables, and the voltage responses from the balance measurement bridges as the dependent variables. While this RCM is important, when the balance is delivered to the facility for use during testing it is used in a manner in which the bridge responses are the independent variables, and the loads computed using the RCM are the dependent variables. As a result of this, it is critical to transform the RCM into what is known as the data reduction matrix (DRM $)^{21,25}$. The balances end function is to measure forces/moments as a function of the measured bridge responses, therefore it is necessary to perform an iterative computation procedure in order to transform the RCM into the DRM. Detail on these computations, and implementation at the facility will be described in the next section.

Table 11: NTF-117S Pressure Tare Calibration Regression Coefficients

\begin{tabular}{|c|c|c|c|c|c|}
\hline GAGE_OUT_NAME & rNF & rPM & rYM & rRM & rAF \\
\hline INTERCEPT & $1.61727 \mathrm{E}+02$ & $-1.24569 \mathrm{E}+02$ & $-1.39605 \mathrm{E}+02$ & $-6.35135 \mathrm{E}+01$ & $2.18983 \mathrm{E}+01$ \\
\hline NF (x1) & $1.10958 \mathrm{E}-01$ & $-8.61028 \mathrm{E}-04$ & $7.86034 \mathrm{E}-05$ & $8.04556 \mathrm{E}-04$ & $1.45923 \mathrm{E}-04$ \\
\hline PM (x3) & $7.63063 \mathrm{E}-06$ & $1.90528 \mathrm{E}-02$ & $-2.12038 \mathrm{E}-05$ & $-2.52789 \mathrm{E}-05$ & $-1.17604 \mathrm{E}-05$ \\
\hline YM (x5) & 0 & $-2.35561 \mathrm{E}-05$ & $2.88012 \mathrm{E}-03$ & $9.55517 \mathrm{E}-05$ & $6.90880 \mathrm{E}-05$ \\
\hline RM (x4) & $5.97836 \mathrm{E}-06$ & 5.28222E-08 & $-6.55755 \mathrm{E}-06$ & $2.76258 \mathrm{E}-03$ & $-2.61533 \mathrm{E}-06$ \\
\hline AF (x2) & $1.12074 \mathrm{E}-02$ & $-2.30562 \mathrm{E}-04$ & $5.09453 \mathrm{E}-03$ & 0 & $6.56795 \mathrm{E}-01$ \\
\hline BelP (x6) & $-2.17716 \mathrm{E}-02$ & $-9.99133 \mathrm{E}-04$ & $2.40943 \mathrm{E}-05$ & $-1.22247 \mathrm{E}-02$ & $-6.34672 \mathrm{E}-03$ \\
\hline BelT (x7) & $-5.08414 \mathrm{E}-03$ & $6.94177 \mathrm{E}-03$ & $-6.85808 \mathrm{E}-04$ & $1.38419 \mathrm{E}-03$ & $-1.47881 \mathrm{E}-02$ \\
\hline NF*NF & 0 & $1.36242 \mathrm{E}-08$ & 0 & 0 & 0 \\
\hline $\mathbf{P M} * \mathbf{P M}$ & $-3.00296 \mathrm{E}-10$ & 0 & $-4.29171 \mathrm{E}-11$ & $-2.10387 \mathrm{E}-10$ & 0 \\
\hline $\mathbf{Y M}$ :YM & 0 & 0 & $-3.77811 \mathrm{E}-11$ & $4.52053 \mathrm{E}-10$ & 0 \\
\hline $\mathbf{R M} * \mathbf{R M}$ & 0 & 0 & 0 & $4.43658 \mathrm{E}-12$ & 0 \\
\hline $\mathbf{A F} * \mathbf{A F}$ & 0 & 0 & 0 & 0 & 0 \\
\hline BelP*BelP & $-3.42372 \mathrm{E}-06$ & 0 & $-3.80904 \mathrm{E}-07$ & 0 & $5.50889 \mathrm{E}-06$ \\
\hline NF*PM & 0 & $3.42919 \mathrm{E}-09$ & $-9.55530 \mathrm{E}-10$ & 0 & $-8.88327 \mathrm{E}-09$ \\
\hline NF*YM & 0 & 0 & 0 & 0 & 0 \\
\hline NF*RM & 0 & 0 & 0 & 0 & 0 \\
\hline $\mathrm{NF}^{*} \mathrm{AF}$ & 0 & 0 & $-1.44288 \mathrm{E}+01$ & 0 & 0 \\
\hline NF*BelP & $-3.99136 \mathrm{E}-07$ & 0 & $-3.98825 \mathrm{E}-08$ & 0 & $4.86459 \mathrm{E}-07$ \\
\hline NF*BelT & 0 & $-6.29626 \mathrm{E}-06$ & $8.73617 \mathrm{E}-07$ & $-3.51847 \mathrm{E}-06$ & $1.25740 \mathrm{E}-06$ \\
\hline PM*YM & 0 & 0 & 0 & 0 & 0 \\
\hline PM*RM & 0 & $-6.43266 \mathrm{E}-11$ & $4.22236 \mathrm{E}-11$ & 0 & $2.80147 \mathrm{E}-10$ \\
\hline PM*AF & 0 & 0 & 0 & 0 & 0 \\
\hline PM*BelP & 0 & 0 & 0 & 0 & $-5.45154 \mathrm{E}-08$ \\
\hline PM*BelT & $4.04374 \mathrm{E}-07$ & 0 & 0 & 0 & 0 \\
\hline YM*RM & 0 & 0 & 0 & 0 & 0 \\
\hline $\mathbf{Y M}$ MF & 0 & 0 & 0 & 0 & $-7.60783 \mathrm{E}-09$ \\
\hline YM*BelP & 0 & 0 & 0 & $3.41352 \mathrm{E}-08$ & 0 \\
\hline YM*BelT & 0 & 0 & 0 & $-3.32922 \mathrm{E}-06$ & 0 \\
\hline $\mathbf{R M}$ *AF & 0 & 0 & $4.22268 \mathrm{E}-09$ & 0 & 0 \\
\hline RM*BelP & 0 & 0 & $9.36478 \mathrm{E}-10$ & $-4.48058 \mathrm{E}-09$ & 0 \\
\hline RM*BelT & 0 & 0 & 0 & 0 & 0 \\
\hline AF*BelP & 0 & 0 & $-9.47774 \mathrm{E}-08$ & 0 & $-5.37341 \mathrm{E}-06$ \\
\hline AF*BelT & $-3.01819 \mathrm{E}-05$ & $-7.46821 \mathrm{E}-06$ & $1.01104 \mathrm{E}-05$ & 0 & $2.30568 \mathrm{E}-04$ \\
\hline BelP*BelT & 0 & 0 & $1.463930-5$ & 0 & $-1.75377 \mathrm{E}-04$ \\
\hline
\end{tabular}

Table 12 below expresses the regression coefficients from Table 11 in terms of percent of full-scale effect, based on the full-scale load component for each term. It is useful to look at the percent contribution of each term both for diagnostic purposes, and to determine which terms are the most dominant in each model. For the rNF bridge, the NF coefficient has a $100 \%$ full-scale contribution, as would be expected because the balance is primarily a linear device, so the linear NF term should be dominant. Also, notice the linear BelP model term for the rNF bridge, it has a $-1.96 \%$ contribution within the model of the response, indicating that the influence of the bellows pressure on the behavior of the rNF response is significant, and relatively large compared to other interaction terms. Many of the BelP and BelT model terms for each response are significant, revealing that the addition of the bellows into the system has an effect on the overall performance characteristic of the balance. While ideally it would be preferred for the introduction of the bellows to have zero influence on the balance, these results show that the influence is significant, and performing this calibration was necessary in order to properly characterize the balance/SMSS integrated system. 
Table 12: Percent of Full-Scale Effects for Model Terms

\begin{tabular}{|c|c|c|c|c|c|}
\hline & rNF & rPM & rYM & rRM & rAF \\
\hline GAGE OUT NAME & \% FS Effect & \% FS Effect & \% FS Effect & \% FS Effect & \% FS Effect \\
\hline INTERCEPT & 12.15 & -7.27 & -44.07 & -3.44 & 1.85 \\
\hline NF (x1) & 100.00 & -0.60 & 0.30 & 0.52 & 0.15 \\
\hline PM (x3) & 0.05 & 100.00 & -0.60 & -0.12 & -0.09 \\
\hline YM (x5) & 0.00 & -0.15 & 100.00 & 0.57 & 0.64 \\
\hline RM (x4) & 0.30 & 0.00 & -1.38 & 100.00 & -0.15 \\
\hline $\mathrm{AF}(\mathrm{x} 2)$ & 1.52 & -0.02 & 2.89 & 0.00 & 100 \\
\hline BelP (x6) & -1.96 & -0.07 & 0.01 & -0.79 & -0.64 \\
\hline BelT (x7) & -0.03 & 0.03 & -0.02 & 0.01 & -0.1 \\
\hline NF*NF & 0 & 0.11 & 0 & 0 & 0 \\
\hline PM*PM & -0.18 & 0 & -0.11 & -0.09 & 0 \\
\hline YM*YM & 0 & 0 & -0.14 & 0.30 & 0 \\
\hline RM*RM & 0 & 0 & 0 & 0.11 & 0 \\
\hline $\mathrm{AF}^{*} \mathrm{AF}$ & 0 & 0 & 0 & 0 & 0 \\
\hline BelP*BelP & -0.37 & 0 & -17.00 & 0 & 0.67 \\
\hline NF*PM & 0 & 0.22 & -0.33 & 0 & -0.81 \\
\hline NF*YM & 0 & 0 & 0 & 0 & 0 \\
\hline NF*RM & 0 & 0 & 0 & 0 & 0 \\
\hline NF*AF & 0 & 0 & -0.44 & 0 & 0 \\
\hline NF*BelP & -0.43 & 0 & -0.18 & 0 & 0.59 \\
\hline NF*BelT & 0 & -0.35 & 0.26 & -0.18 & 0.1 \\
\hline PM*YM & 0 & 0 & 0 & 0 & 0 \\
\hline PM*RM & 0 & -0.23 & 0.80 & 0 & 1.43 \\
\hline PM*AF & 0 & 0 & 0 & 0 & 0 \\
\hline PM*BelP & 0 & 0 & 0 & 0 & -0.5 \\
\hline PM*BelT & 0.22 & 0 & 0 & 0 & 0 \\
\hline YM*RM & 0 & 0 & 0 & 0 & 0 \\
\hline YM*AF & 0 & 0 & 0 & 0 & -0.13 \\
\hline YM*BelP & 0 & 0 & 0 & 0.24 & 0 \\
\hline YM*BelT & 0 & 0 & 0 & -1.59 & 0 \\
\hline $\mathrm{RM}^{*} \mathrm{AF}$ & 0 & 0 & 1.61 & 0 & 0 \\
\hline RM*BelP & 0 & 0 & 0.24 & 0 & 0 \\
\hline RM*BelT & 0 & 0 & 0 & 0 & 0 \\
\hline AF*BelP & 0 & 0 & -0.06 & 0 & -0.98 \\
\hline AF*BelT & -0.33 & -0.06 & 0.46 & 0 & 2.81 \\
\hline BelP*BelT & 0 & 0 & 0.44 & 0 & -1.42 \\
\hline
\end{tabular}

After constructing the models, each was assessed by back-computing the residuals (difference between applied theoretical load and computed load by passing the responses through the RCM) and investigating the residual plots for each response. The traditional method for computing balance accuracy is to computed the residuals, and construct a two-sigma bound on each response based on those residuals. Figure 18 below shows the residuals plots for each measurement component (computed residual as \% of full-scale vs. applied load). The horizontal dotted lines within each plot represent the +/- one-sigma accuracy envelope, and the red regions for rNF, rRM, and rAF indicate applied loadings that have a magnitude greater than $105 \%$ of the full-scale load capacity for that load component.

It is apparent from the residual plots that many loadings on the rNF and rAF components contain relatively high residual values, indicating a possible error in the theoretically applied loads during the load series. It should be noted here that the residual plots in Figure 18 contain applied load factor settings that have not been corrected for any fixture deflections while under load. Recall that the fixture was designed to incorporate an AMS near the region of load application, which was to be used to compute the deflections at the load point during each series - to this point the computations in the data reduction/analysis code have not been completed to correct for this. Future calibrations will have this analysis module completed, and any future calibrations will implement this correction. It is also worth noting again that all pressurized loadings the effect of the pressurization on the bellows resulted in a an increased temperature of the bellows, which did not always settle back out to the original level at the end of each load series. As a result of this, the end points within each load series contained an induced error due the fact that this non-returning temperature shift caused small offsets in the return electrical outputs within each series. The fact that the start/end un-loaded measurements within each series have an offset results in a small magnitude of induced error. During data reduction the first zero in each series was used as the reference for the tare computations, future calibrations might involve either ignoring the final zero in each load series or averaging the start/end un-loaded zeros. 
The accuracies depicted in Figure 19 are quoted as one-sigma values. The final two-sigma values for each component are computed and shown in Table 13. The accuracy for rAF is slightly higher than is typically expected for most traditional balance calibrations/applications, but in the case of this calibration the results in the next section will show drastic improvement when using this pressure tare calibration matrix as opposed to using the balance only calibration which was generated based on loadings of the balance outside of the SMSS.
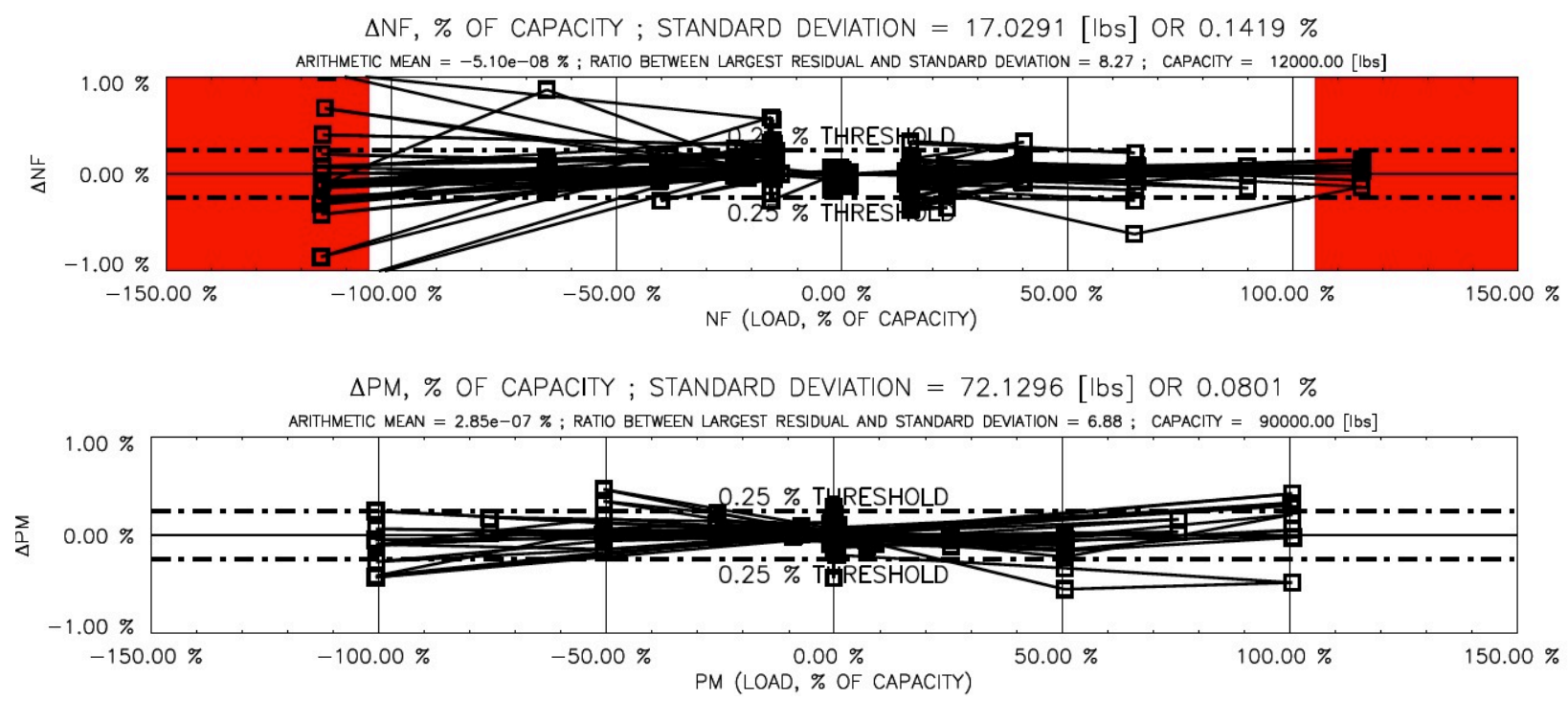

$\triangle \mathrm{YM}, \%$ OF CAPACITY ; STANDARD DEVIATION $=103.0555$ [in-Ibs] OR $0.0937 \%$
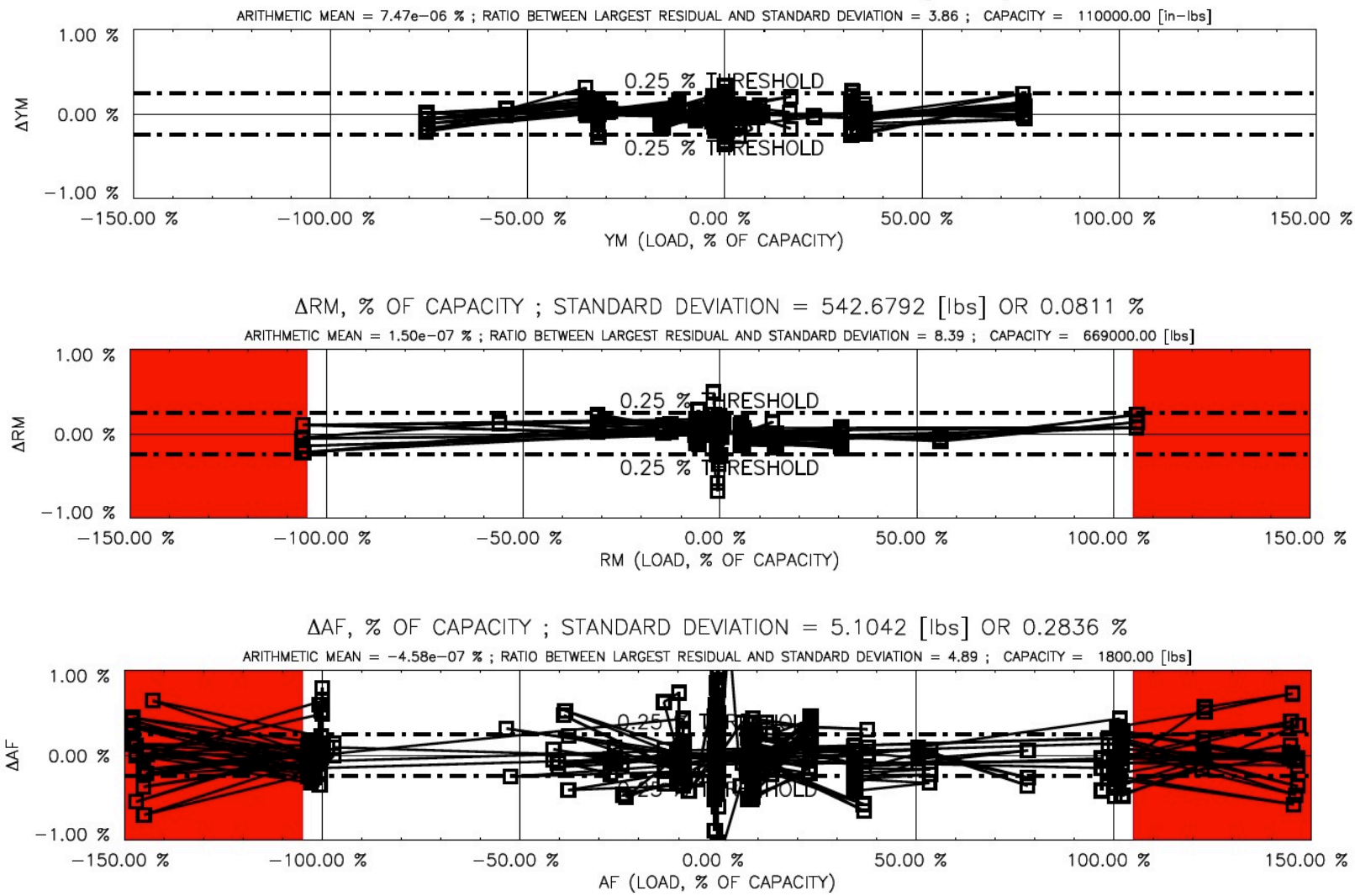

Figure 19. Load vs. Applied Load Back-Computed Residuals

American Institute of Aeronautics and Astronautics 
Table 13 also included the quoted two-sigma accuracy values for each component when using the calibration matrix/models to estimate the independent confirmation points performed during teach WP data set, and the confirmation points completed at the intermediate temperature setting of approximately $45-50^{\circ} \mathrm{F}$. Using these confirmation points as independent validations of the resulting calibration models, the final residuals are computed and the two-sigma values tabulated bellows closely match those values computed from the model design point. This signifies the calibration models are capable of being used to predict loadings based on input responses (bridge outputs) that are different from any set of responses obtained from the model design points. This is a method commonly employed at NASA Langley for verifying the prediction capability of the final calibration.

Table 13: Accuracy of NTF-117S Balance Responses (Model \& Confirmation)

\begin{tabular}{|c|c|c|c|c|c|}
\hline & rNF & rPM & rYM & rRM & rAF \\
\hline $\begin{array}{c}\text { 2-Sigma, \% Full-Scale, } \\
\text { Model Design Points }\end{array}$ & 0.284 & 0.160 & 0.195 & 0.162 & 0.567 \\
\hline $\begin{array}{c}\text { 2-sigma, \% Full-Scale, } \\
\text { Confirmation Points }\end{array}$ & 0.228 & 0.135 & 0.205 & 0.164 & 0.509 \\
\hline
\end{tabular}

\section{Pressure Tare Correction Implementation at the NTF}

As discussed in the previous section, it is required to iteratively compute the DRM in order to be able to estimate loads based on measured responses ${ }^{25}$. The general form of the balance response calibration equation is:

$$
\vec{R}=C_{1} \vec{F}+C_{2} \tilde{F}
$$

where $C_{l}$ is the squared matrix from the RCM that contains the linear $1^{\text {st }}$ order terms, $\vec{F}$ is a matrix of the component loadings applied during the calibration, $C_{2}$ is the interaction matrix portion of the RCM containing all non-linear terms, and $\widetilde{F}$ is a matrix composed of all non-linear combinations of the component loads. In order to use this equation to estimate the loads from the bridge outputs, this equation is typically solved in an iterative fashion as follows:

$$
\vec{F}=C_{1}^{-1} \vec{R}-C_{1}^{-1} C_{2} \tilde{F}
$$

The addition of the pressure tare and temperature tare calibration terms computed from the calibration described above, equation (12) is modified to include an additional set of terms to capture these pressure/temperature tare terms. These additional terms involving only the pressure/temperature coefficient terms are combined in the $C 3$ matrix:

$$
\vec{R}=C_{1} \vec{F}+C_{2} \tilde{F}+C_{3} \tilde{G}
$$

where $\tilde{G}$ is a matrix of pressure/temperature factor settings. The updated equation for estimating the loads then becomes:

$$
\vec{F}=C_{1}^{-1} \vec{R}-C_{1}^{-1} C_{2} \tilde{F}-C_{1}^{-1} C_{3} \tilde{G}
$$

As seen from above, since the $\vec{R}$ and $\widetilde{G}$ matrices contain both responses and applied settings that do not require correction as the are explicitly known, they require no iteration. These terms can be grouped together:

$$
\vec{F}=C_{1}^{-1}\left[\vec{R}-C_{3} \tilde{G}\right]-C_{1}^{-1} C_{2} \tilde{F}
$$

Using equation (16) it is clear that the first group can be directly computed, while the second group containing $C_{1}^{-1} C_{2} \tilde{F}$ needs to be iteratively solved. Combining the $C_{1}^{-1}$ and $C_{1}^{-1} C_{2}$ into a single matrix construction results in the DRM that has been referred to. This DRM constructed during the data calibration analysis, and then delivered to the wind-tunnel facility for use during testing in order to be able to directly compute measured forces/moments imparted on the balance by measuring the bridge voltage responses. 
Traditionally at NASA Langley a standard $2^{\text {nd }}$-order quadratic calibration matrix has always been constructed and used by all facilities during testing. This new pressure tare calibration capability at the NTF required implementing a capability within the data reduction software for implementing the DRM format as described in the AIAA Balance Calibration Recommended Practice Document ${ }^{25}$. An effort was undertaken at the facility to modify the data reduction software to read in a non-standard calibration matrix formatted to match AIAA format. This required a significant level of effort from personnel at the facility to write new code, integrate this code into the data reduction methodology at the facility, and completely validate/verify proper computations throughout. After integrating the capability to allow for reducing data with calibration models of greater size (including pressure/temperature tare effects), the newly developed DRM from the NTF-117S pressure tare calibration was used at the facility for wind-tunnel test data correction.

Recent testing at the NTF used the NTF-117S semi-span balance, and the high-pressure bellows configuration for evaluating new AFC techniques. Figure 20 reveals data from check-out tests of the SMSS/balance after assembling the SMSS into the tunnel test section, with the test model mounted to the mechanism. Figure 20a plots out the computed loads for both the rNF and rAF bridges, where the balance is in an unloaded state and the bellows is pressurized incrementally from 0 to $1100 \mathrm{psia}$ (dotted red lines represent the two-sigma accuracy band computed from the recent pressure tare calibration, blue dotted lines represent the two-sigma accuracy from the balance only calibration). The opened circle curve reveals the computed balance loadings using the previously generate balance only calibration (no terms included for pressure correction). It is obvious that the balance only calibration makes no attempt to correct for the applied bellow pressures, as the computed balance AF/NF loads deviate outside of the balance accuracy quotes when bellows pressure exceeds 200 psia. The close circle curve reveals the computed balance loadings using the newly generated pressure tare calibration. The computed AF/NF loads are clearly being corrected for the applied bellows pressure, and slightly deviate outside of the newly computed two-sigma accuracies.

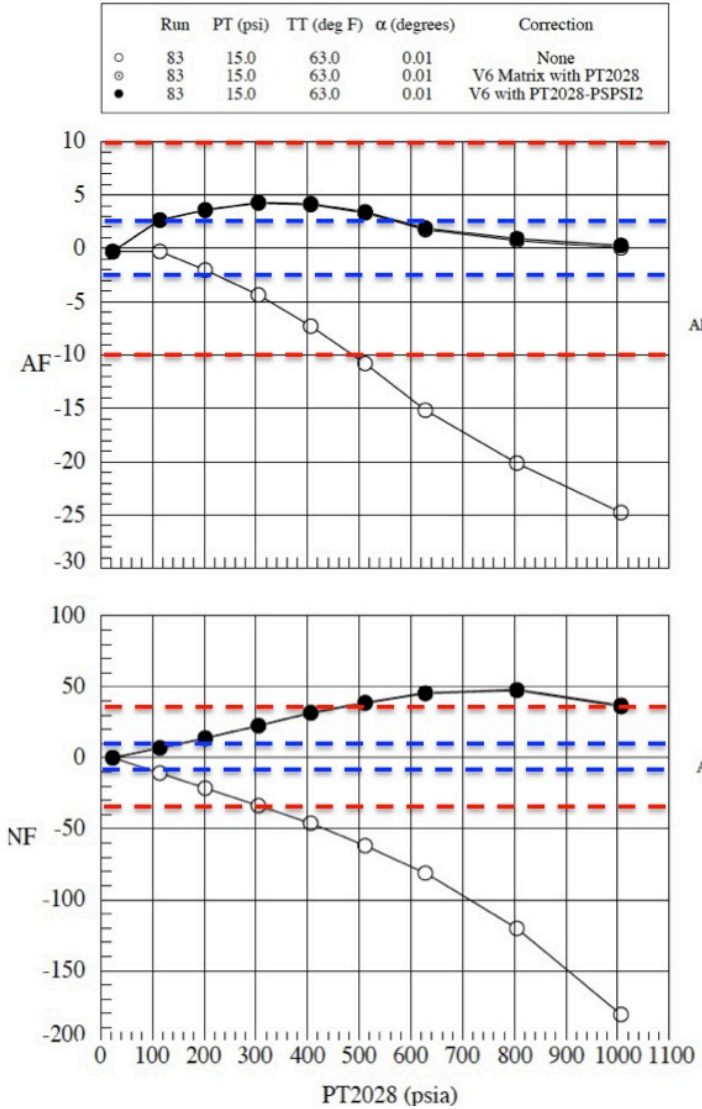

a)
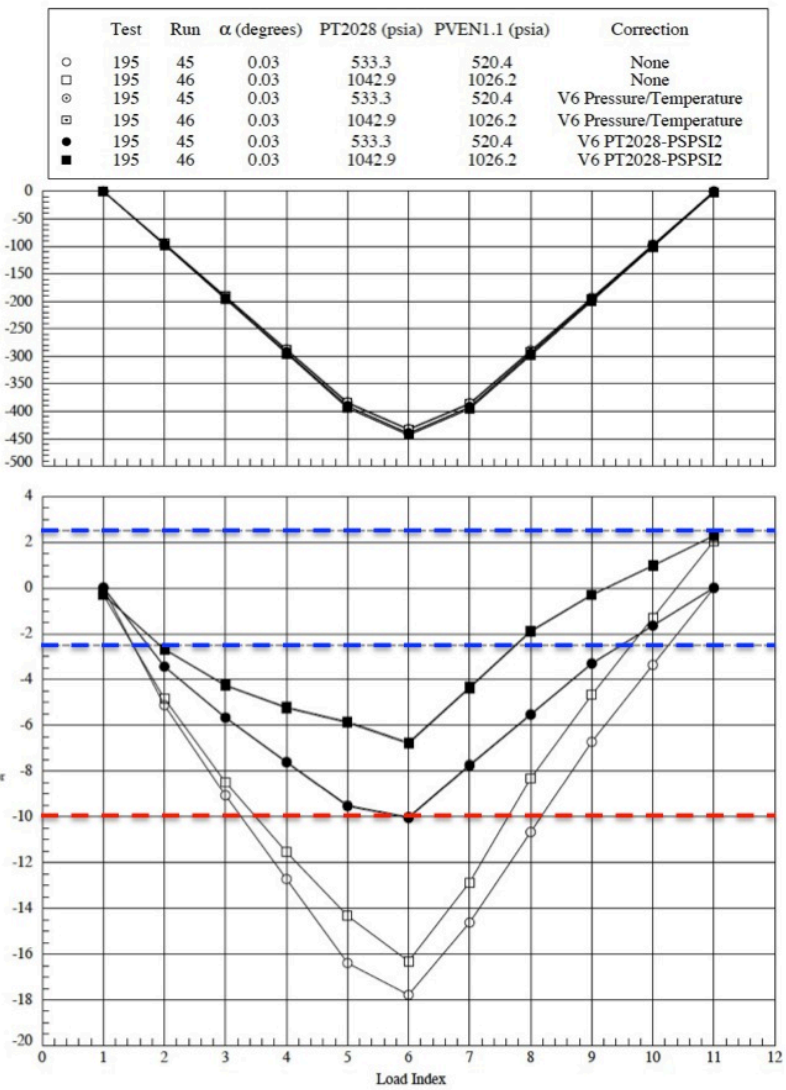

b)

Figure 20. Residual Analysis from Tunnel Test Data, a) Unloaded Pressure Only AF \& NF Residuals, b) AF Model/Balance Loading Residuals 
Figure 20 reveals the computed residuals from a single series of -AF loadings completed on the balance/model assembly in the tunnel test section, where $-\mathrm{AF}$ loadings were completed while the bellows was constantly pressurized at both 500 and 1000 psia. The applied loads are in the upper section of Figure 20b, and the residuals are shown in the bottom section of $20 \mathrm{~b}$ (dotted red lines represent the two-sigma accuracy band computed from the recent pressure tare calibration, blue dotted lines represent the two-sigma accuracy from the balance only calibration). The opened circles/boxes represent the computed residuals for both loading series at $500 \& 1000 \mathrm{psi}$, respectively, processing the balance responses with the balance only calibration. Using the balance only calibration, the computed residuals fall outside of the two-sigma values from this calibration (blue dotted lines). The closed circles/boxes represent the computed residuals for both loading series at $500 \& 1000$ psi, respectively, processing the balance responses with the pressure tare calibration data. When using the pressure tare calibration matrix, it is clear that the computed residuals significantly decreased when compared to using a matrix that makes no attempt to correct for the bellows pressures, and the residuals fall within the accuracy bounds (red dotted lines) generated from the recent calibration. These loadings were computed in the test section by applying -AF loadings over a pulley system, therefore it is likely that the load application/method system contributes to the magnitude of the residuals.

The results presented below include a small sample set of replicated high-Reynolds number test runs performed during testing, and these results will simply compare the effect of the calibration results through a progression to reveal the impact of the newly completed pressure tare calibration on the results to date. The initial repeat residual analysis was performed by processing the test data with the original balance calibration matrix, which was created from the balance only calibration outside of the SMSS (no bellows), therefore this calibration matrix does not include any pressure/temperature tare corrections. The results from this analysis are shown in Figure 21a below, revealing the drag coefficient residuals for these repeat runs fall within a two-sigma range of approximately $+/-93$ counts. It would be expected to have constant variance in the computed drag coefficient residuals, but from this plot is clear the residuals are non-constant with the higher alpha settings exhibiting higher residuals (near linear trend for each set of runs using similar wind-off zero (WOZ) references).

The test replicate runs were then processed with the DRM described in the previous section (termed the V6 matrix by the facility). The results from this analysis are shown in Figure $21 \mathrm{~b}$ below, revealing the drag coefficient residuals for these repeat runs fall within a two-sigma range of approximately $+/-30$ counts.

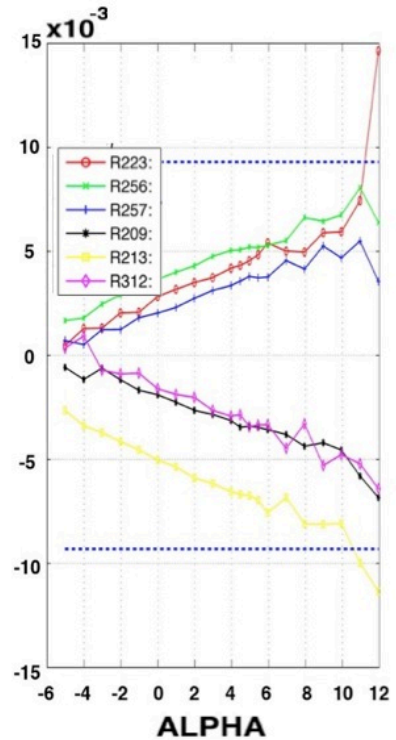

(a)

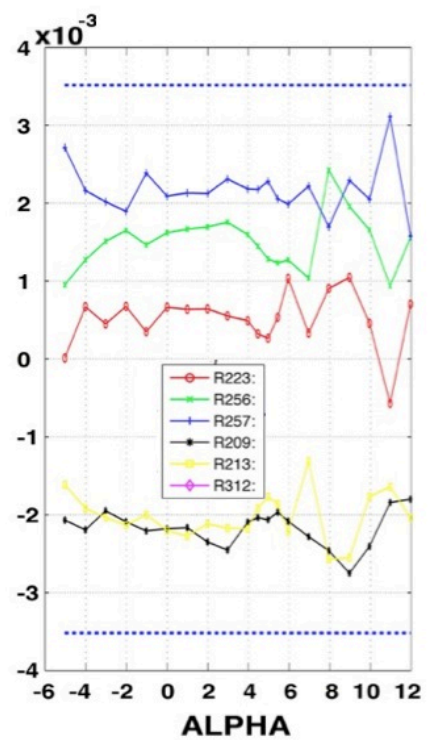

(b)

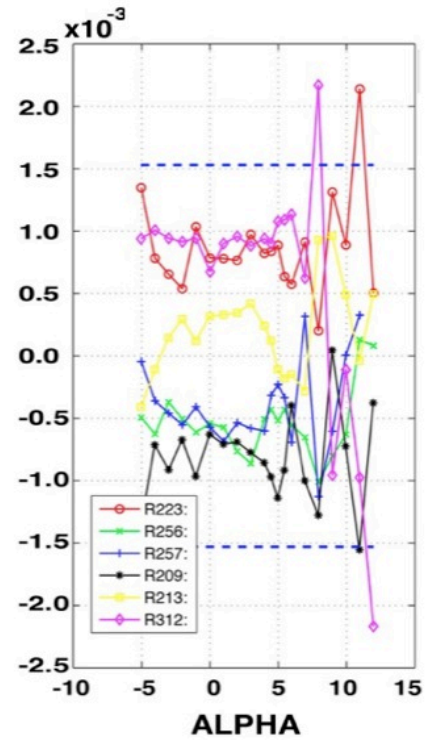

(c)

Figure 21. Cd Residuals, a) original balance calibration, b) new pressure tare calibration, c) new pressure tare calibration with applied momentum tare correction

During the test it was decided to run a set of set of active blowing pitch polars in order to be able to generate an approximate axial force momentum thrust correction. During the residual analysis, it was noticed that using a set of 
pressurized WOZ's to reduce the data yielded decreased and more constant residual values. The final results shown above in Figure 21c were processed with the final pressure tare DRM, applied axial moment thrust corrections, and a complete set of pressurized WOZ points. When applying all of these corrections/parameters, the resulting residuals for these six repeat runs fall within a two-sigma range of approximately $+/-15$ counts.

While in theory, the use of a pressurized or unpressurized WOZ should be accounted for by suitably translating for initial load (and pressure/temp terms), in practice the use of pressurized WOZ's was found to be preferable. At this time, the advantage of using pressurized WOZs is attributed to an observation made during calibration that after unpressurizing the bellows, a large amount of time ( 15-20 mins) was required even after bellows temperature neared equilibrium for the balance electrical zeros to stabilize.

Lastly, a preliminary analyses of the axial momentum tare corrections was performed. Sets of back-to-back replicated runs were selected, and the residuals without the correction are shown in 22a below. These residuals reveal a bias offset between the residual curves, resulting in an approximate two-sigma bound of $+/-27$ counts. After applying the axial thrust correction, the back-to-back residuals reduce down to approximately $+/-5$ counts, as seen in Figure 22b. Based on this correction, it is also clear from the residual plots that this correction may be over correcting the test data, but shows significant improvement by combining the static pressure tare calibration with a simplified axial thrust momentum tare correction. It is postulated that with further refinement, and the capability for performing a more thorough momentum tare calibration, it is possible for further increasing test data quality by improving the measurement capability.

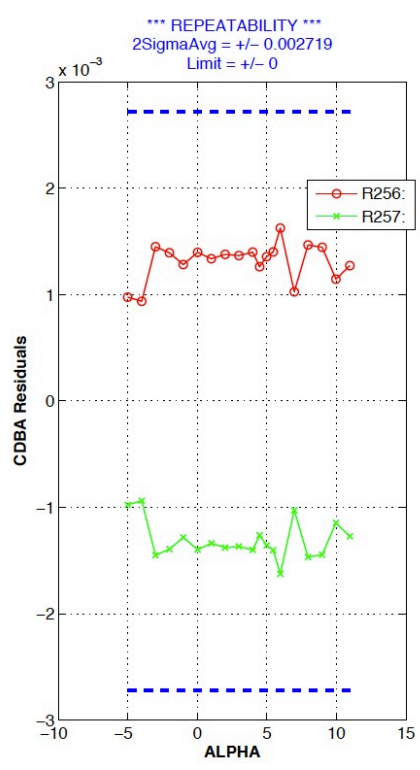

a)

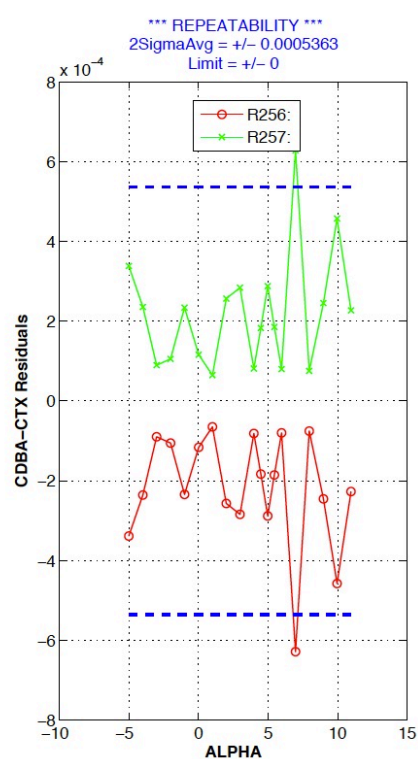

b)

Figure 22. Back-to-Back Tunnel Runs, a) Without Thrust Correction, b) With Thrust Correction

\section{Future Work}

As discussed in the previous sections, significant progress has been made at the NASA NTF to establish the capability for characterizing externally mounted semi-spans under the influence of pressure tare effects from highpressure air bellows. The preliminary data revealed in the previous sections shows a factor of 6-7 reduction in the computed drag coefficients, for a specified set of replicated test runs distributed throughout the test matrix, by calibrating the semi-span balance as a complete system within the SMSS. While significant progress has been made to this point, several key pieces of work in the next several months will be completed in order to further improve data quality at the facility. This work includes:

1. A new high-pressure adapter coupling (bellows replacement) has been designed/fabricated for use during next calibration/test

2. Balance heater control recirculation system (BCRS) has been redesigned 
3. New calibration load schedule being developed to assess potential higher order calibration terms

4. Upgraded data processing code to correct for fixture deflections

5. Potentially developing capability for performing momentum tares (loaded and un-loaded) at NTF

The new high-pressure adapter coupling has been designed as a 'stiff' coupling that replaces the previous convoluted pressure bellows arrangement. The previous bellows used for testing and calibration worked reasonably well, but as described there were some repeatability/hysteresis effects observed during use that led to the design of the new coupling. While the new pressure adapter coupling does not contain any convolutes/spring elements to reduce the total stiffness contribution observed by the balance, the new coupling was designed to reduce this stiffness (as much as possible while remaining structurally capable under pressure loads), and the research team believes that the increased system stiffness (and potential for reduced balance output measurement sensitivity) will not impact use during testing. It is believed that while the overall system stiffness will slightly increase, the new pressure adapter coupling should result in better data repeatability and overall performance stability. Figure 20 shows a comparison between the previous convoluted bellows and the new pressure adapter coupling. The new coupling is in the process of being instrumented with a suite of temperature sensors to better capture the temperature state of the coupling during calibration testing, and is also being modified to incorporate primary/back-up pressure ports in both the high mass-flow and low mass-flow legs of the coupling to better measure the actual total pressure during use. These upgrades will be completed prior to the upcoming calibration in Summer 2012.

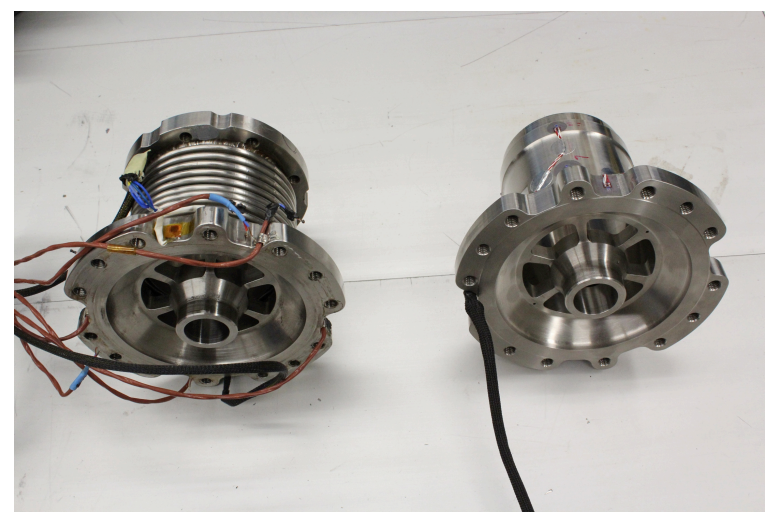

Figure 20. Convoluted Bellows (left) and High-Pressure Air Adapter Coupling (right)

During the facility/SMSS upgrade to integrate the high-pressure air system for use during AFC testing, the internal balance heater control recirculation system (BCRS) was disassembled. The BCRS was used during previously semi-span testing to elevate and hold the balance temperature stable to approximately $100^{\circ} \mathrm{F}+/-2^{\circ} \mathrm{F}$ during wind tunnel testing. The BCRS is being redesigned to allow for closed-loop recirculating blower air through the internal cavity of semi-span balances within the SMSS, to allow for precisely controlling the temperature of the balance within $\mathrm{a}+/-2^{\circ} \mathrm{F}$ range during both calibration and tunnel testing. It was observed during the initial pressure tare calibration that the balance had a small gradient across that was on the order of $2-3^{\circ} \mathrm{F}$ (from metric to the nonmetric flange ends), and that the termparure of the balance fluctuated on the order of $+/-5^{\circ} \mathrm{F}$ due to the cold air from the vortex cooler system conducting through the SMSS back to the balance. While the calibration data did not reveal any significant issues from these thermal impacts, it is desired to more accurately control the balance temperature, and to simulate during calibration how the balance will be used during testing - which will result in a more accurate and representative calibration.

Results from initial calibration effort reveals potential for some higher-order terms (three-factor interactions, cubic terms) for several responses. The experimental design for the initial calibration was designed to support a quadratic calibration model, but due to the additional of additional calibration loadings (start/end points within series) there were additional degrees of freedom (dof) used to test for higher-order term significance. The results from this analysis are not shown here, but the next calibration (with the pressure adapter coupling) will involve an 
initial assessment to determine whether this higher-order behavior is significant, and whether or not the calibration design needs to be further updated to capture this system behavior.

\section{Conclusion}

It is typical that most balance calibrations are performed where only the effects of the applied loads are considered to impact the output of the balances strain gaged measurement bridges. In some instances it is found that other factors influence the overall behavior of the system, in our case the introduction of the bellows into the system impacted the behavior of the balance due to applied bellows pressures and operating temperatures. Recent work at NASA Langley Research Center has been conducted in the area of developing methodologies for calibrating force measurement systems in the presence of these additional factors.

As discussed, it was found during the work at the NTF that the influence of the high-pressure bellows introduced into the semi-span measurement system impacted the performance behavior of the system. After considerable amount of preliminary research/testing, it was decided to pursue the design and development of both calibration hardware and methodology for characterizing the facilities external semi-span balances while considering bellows pressure and temperature effects. It has been shown that the calibration results from the calibration detailed in this report show a significant increase in the data quality resulting from wind-tunnel tests implementing this new calibration matrix.

While the detail presented here are applies directly to a specific type of force measurement system (external semi-span balance), these techniques can be applied to any type of force measurement system calibration. The principles described can easily be modified to expand into other applications, with modifications to take into consideration available hardware and any restrictions.

\section{Acknowledgments}

The author would like to express sincere appreciation to the group of personnel, both NASA and contractors, who contributed to the development of this new calibration capability. The scope of this project required open lines of communication and cooperation amongst many organizations/contractors in order to successfully complete the development of both the new semi-span balance, and the check-load stand capability. The many personnel involved contributed to the mechanical design, fabrication, instrumentation, calibration, facility upgrades (hardware, software, data acquisition) and overall engineering expertise required in order to provide NASA with a new semi-span measurement capability for the NTF. The project has been supported and funded by the National Force Measurement Technology Capability (NFMTC), the Aeronautics Testing Program (ATP), and the Ground Facilities and Testing Directorate (GFTD).

\section{References}

${ }^{1}$ Millholen II, W. E., Jones, G. S., Cagle, C. M., "NASA High-Reynolds Number Circulation Control Research - Overview of CFD and Planned Experiments", AIAA-2010-344, January 2010.

${ }^{2}$ Lynn, K. C., "Development of the NTF-117S Semi-Span Balance", AIAA 2010-4542, July 2010.

${ }^{3}$ Gatlin, G. M., Parker, P. A., Owens Jr., L. R., "Development of a Semi-Span Test Capability at the National Transonic Facility", AIAA 2001-0759, January 2001.

${ }^{4}$ Gatlin, G. M., Tomek, W. G., Payne, F. M., Griffiths, R. C., "Recent Improvements in Semi-Span Testing at the National Transonic Facility", AIAA 2006-508, January 2006.

${ }^{5}$ Gatlin, G. M., Parker, P.A., Owens Jr., L. R., “Advancement of Semispan Testing at the National Transonic Facility", Journal of Aircraft, Vol. 39, No. 2, March-April 2002, pp. 339-353.

${ }^{6}$ Hufnagel, K., Rebstock, R., Zhai, J., "Half-Model-Balance for the Cologne-Cryogenic-Wind-Tunnel Development and Test Results", $18^{\text {th }}$ International Congress on Instrumentation in Aerospace Simulation Facilities, Onera, Toulouse, France, June 1417 1999, pp. 32.1-32.7.

${ }^{7}$ Gatlin, G. M., McGhee, R. J., "Experimental Investigation of Semispan Model Testing Techniques", Journal of Aircraft, Vol. 34, No. 4, July-August 1997, pp. 500-505.

${ }^{8}$ Marchman, J. F., Gunther, C. L., Gundlach, J. F., "Semi-Span Testing at Low Reynolds Number", AIAA 1998-0608, January 1998.

${ }^{9}$ Campell, J. F., "The National Transonic Facility - A Research Perspective”, AIAA 1984-2150, August 1984.

${ }^{10}$ Wahls, R. A., "The National Transonic Facility: A Research Retrospective", AIAA 2001-0754, January 2001. 
${ }^{11}$ Ferris, A. T., "Strain Gauge Balance Calibration and Data Reduction at NASA Langley Research Center", $1^{\text {st }}$ International Symposium on Strain Gauge Balances, Pt. 2, March 1999, pp. 565-572.

${ }^{12}$ Rhew, R. D., "NASA LaRC Strain Gage Balance Design Concepts", $1^{\text {st }}$ International Symposium on Strain Gauge Balances, Pt. 2, March 1999, pp. 525-541.

${ }^{13}$ Englar, R. J., "Two-Dimensional Transonic Wind Tunnel Tests of Three 15-Percent-Thick Circulation Control Airfoils", Naval Ship R\&D Center Technical Note AL-182, AD 882-075, Dec. 1970.

${ }^{14}$ Milholen, W.E., Jones, G.S., Chan, D.T., and Goodliff, S.L., "High-Reynolds Number Circulation Control Testing the National Transonic Facility (Invited)", AIAA paper 2012-0103, January 2012, Nashville.

${ }^{15}$ Myers, R. H. and Montgomery, D. C., Response Surface Methodology, John Wiley \& Sons, 2nd ed., 2002.

${ }^{16}$ Montgomery, D., Design and Analysis of Experiments, John Wiley \& Sons, New York, 7th ed., 2009.

${ }^{17}$ Fisher, R. A., Statistical Methods for Research Work, Oliver and Boyd, Edinburgh, 1925.

${ }^{18}$ Kowalski, S. M., Parker, P. A., and Vining, G. G., “Tutorial on Split-Plot Experiments,” Quality Engineering, Vol. 19, 2007, pp. 1-15.

${ }^{19}$ Parker, P. A., Kowalski, S. M., and Vining, G. G., "Unbalanced and Minimal Point Equivalent Estimation of Second-Order Split-Plot Designs," Journal of Quality Technology, Vol. 39, 2007, pp. 376-388.

${ }^{20}$ Parker, P. A., Anderson-Cook, C. M., Robinson, T., and Liang, L., "Robust Split-Plot Designs," Quality and Reliability International, Vol. 24, 2008, pp. 107-121.

${ }^{21}$ Lynn, K. C., Commo, S. A., Parker, P. A., "Wind-Tunnel Balance Characterization for Hypersonic Research Applications," Journal of Aircraft, Vol. 49, 2012, pp. 556-565.

${ }^{22}$ Myers, R. H., Classical and Modern Regression with Applications, Duxbury Press, Belmont, CA, $2^{\text {nd }}$ ed., 1990.

${ }^{23}$ Bergman, R. and Philipsen, I., "An Experimental Comparison of Different Load Tables for Balance Calibration," 7th International Symposium on Strain Gage Balances, April 2010.

${ }^{24}$ Ulbrich, N., "Regression Model Optimization for the Analysis of Experimental Data," 47th AIAA Aerospace Sciences Meeting and Aerospace Exposition, No. 2009-1344, AIAA, Orlando, FL, January 2009.

${ }^{25}$ Recommended Practice: Calibration and Use of Internal Strain Gage Balances with Application to Wind Tunnel Testing, AIAA Standards Series, R-091-2003, AIAA, Reston, VA, 2003. 